OPEN ACCESS

Edited by:

Helene Sanfacon,

Agriculture and Agri-Food Canada

(AAFC), Canada

Reviewed by:

Mazen Alazem,

Seoul National University,

South Korea

Michael Taliansky,

James Hutton Institute,

United Kingdom

Emanuela Noris,

Italian National Research Counci

(CNR), Italy

*Correspondence:

Jeng-Shane Lin

jslin@dragon.nchu.edu.tw:

lineye0220@gmail.com

${ }^{t}$ These authors have contributed

equally to this work

Specialty section:

This article was submitted to

Virology,

a section of the journal

Frontiers in Plant Science

Received: 05 February 2019

Accepted: 26 June 2019

Published: 12 July 2019

Citation:

Tsai W-A, Weng S-H, Chen M-C,

Lin J-S and Tsai W-S (2019) Priming

of Plant Resistance to Heat Stress and Tomato Yellow Leaf Curl Thailand

Virus With Plant-Derived Materials.

Front. Plant Sci. 10:906.

doi: 10.3389/fp/s.2019.00906

\section{Priming of Plant Resistance to Heat Stress and Tomato Yellow Leaf Curl Thailand Virus With Plant-Derived Materials}

\author{
Wei-An Tsai ${ }^{1,2+}$, Sung-Hsia Weng ${ }^{1,3+}$, Ming-Cheng Chen ${ }^{4}$, Jeng-Shane Lin $^{4 *}$ and \\ Wen-Shih Tsai ${ }^{5}$
}

\begin{abstract}
${ }^{1}$ Hualien District Agricultural Research and Extension Station, Council of Agriculture, Executive Yuan, Hualien City, Taiwan, ${ }^{2}$ Queensland Alliance for Agriculture and Food Innovation, The University of Queensland, St Lucia, QLD, Australia, ${ }^{3}$ School of Biological Sciences, The University of Queensland, St Lucia, QLD, Australia, ${ }^{4}$ Department of Life Sciences, National
\end{abstract} Chung Hsing University, Taichung, Taiwan, ${ }^{5}$ Department of Plant Medicine, National Chiayi University, Chiayi City, Taiwan

Plants are often simultaneously exposed to diverse environmental stresses, and can tune suitable responses to them through hormones. Salicylic acid (SA) and jasmonic acid (JA) signaling pathways are known to enhance resistance against heat stress and tomato yellow leaf curl Thailand virus (TYLCTHV) infection. However, there is limited information regarding alternative natural priming agents against heat stress and viruses. In this study, two plant-derived priming agents, eugenol and anise oil, were tested for their roles in conferring thermotolerance and virus resistance in tomato plants. Under heat stress, the survival rates and average fresh weight were higher in plants treated with eugenol or anise oil than in control plants. These two priming agents were further tested for antiviral activities. After TYLCTHV infection, the disease incidence and relative abundance of TYLCTHV were lower in anise oil- and eugenol-treated plants than in control plants. Further analyses revealed that a few SA, JA, and RNA silencing genes were enhanced in the former. Moreover, SA, JA, and $\mathrm{H}_{2} \mathrm{O}_{2}$ contents increased considerably after eugenol and anise oil treatments. Our findings imply that anise oil and eugenol initiated SA- and JA-mediated defenses to promote thermotolerance and antiviral responses of tomato plants.

Keywords: anise oil, eugenol, jasmonic acid, salicylic acid, thermotolerance, tomato (Solanum lycopersicum), tomato yellow leaf curl Thailand virus (TYLCTHV)

\footnotetext{
Abbreviations: AAP, acquisition access period; AGO, argonaute; APX, ascorbate peroxidase; BTH, benzothiadiazole; DAB, 3, 3-diaminobenzidine; DCLs, dicer-like endoribonucleases; dpi, days post-inoculation; hpt, hours post-treatment; GAPDH, glyceraldehyde-3-phosphate dehydrogenase; HR, hypersensitive response; HSFs, heat stress transcription factors; HSPs, heat shock proteins; IAP, inoculation access period; JA, jasmonic acid; MAPK, mitogen-activated protein kinase; MeJA, methyl jasmonate; PCR, polymerase chain reaction; PPO-F, polyphenol oxidase-F; PR, pathogenesis-related gene; PI-II, proteinase inhibitor II; qPCR, quantitative PCR; RDR, RNA-directed RNA polymerase; ROS, reactive oxygen species; RT-PCR, reverse transcription PCR; SA, salicylic acid; SAR, systemic acquired resistance; TMV, tobacco mosaic virus; ToLCTWV, tomato leaf curl Taiwan virus; TSWV, tomato spotted wilt virus; TYLCCNV, tomato yellow leaf curl China virus; TYLCTHV, tomato yellow leaf curl Thailand virus; TYLCV, tomato yellow leaf curl virus; vsiRNAs, viral small interfering RNAs.
} 


\section{INTRODUCTION}

Plants are often exposed to multiple biotic and abiotic stresses throughout their lifespan. Their survival requires sophisticated sensory systems that perceive various stress signals and activate the most appropriate responses at the molecular, cellular, and physiological levels.

Under natural conditions, certain stresses that occur sequentially or simultaneously can enhance plant tolerance to other abiotic or biotic stresses (Foyer et al., 2016; Hossain et al., 2018). Several common signaling components, including ROS, plant hormones, proline, and stress-responsive genes, are triggered to initiate a cross-tolerance mechanism in response to environmental stresses (Yasuda et al., 2008; Islam et al., 2009; Atkinson and Urwin, 2012; Lin et al., 2014). Interestingly, the stimuli that induce plants to enter a primed state are the preceding stresses as well as natural or synthetic chemical compounds (Savvides et al., 2016). The naturally occurring metabolic stimuli include vitamins, hormones, amino acids, growth-promoting molecules, and reactive oxygen-nitrogensulfur species that initiate complex signal transduction pathways and alter gene expression to enhance plant tolerance to abiotic and biotic stresses (Athar et al., 2008; Arnao and HernandezRuiz, 2014; Christou et al., 2014; Li T. et al., 2014; Savvides et al., 2016). In wheat, ascorbate decreases oxidative damage and maintains ion homeostasis under salt stress conditions (Athar et al., 2008). In Arabidopsis thaliana, auxin response factors were shown to influence heat tolerance through regulating plant development and HSP expression (Lin et al., 2018). Additionally, in higher plants, SA and MeJA not only improve heat stress tolerance (Snyman and Cronje, 2008; Clarke et al., 2009; Wang et al., 2010), they also enhance antiviral activities (Calil and Fontes, 2017; Li et al., 2017, 2018). A previous study revealed that a proline treatment of tobacco cells results in increased antioxidant enzyme activities to mediate cadmium stress tolerance (Islam et al., 2009). Other studies proved that melatonin regulates plant growth as well as antioxidative responses in plants (Arnao and Hernandez-Ruiz, 2014, 2018; Zhang et al., 2015), whereas beta-aminobutyric acid promotes biotic and abiotic stress tolerance (Ton et al., 2009; Jisha and Puthur, 2016; Meller et al., 2018). Eugenol (4-allyl-2methoxyphenol) elevates nitric oxide and SA accumulation to mediate resistance to TYLCV in tomato plants (Wang and Fan, 2014; Sun et al., 2016). In addition to naturally occurring stimuli, benzothiadiazole and kresoxim-methyl have been synthesized and applied to induce plant defenses (Filippou et al., 2016).

Plant-derived materials have been used to protect plants from many diseases. For example, cinnamon oil, fennel oil, origanum oil, and thyme oil exhibit antifungal activities against Fusarium species (Park et al., 2017), whereas lemon oil can inhibit the growth of three phytopathogenic fungi (Eutypa sp., Botryosphaeria dothidea, and Fomitiporia mediterranea) that infect grapevine wood (Ammad et al., 2018). In addition to their direct antimicrobial effects, plant-derived materials have also been reported to synergistically and directly activate or prime treated plants to promote responses to biotic and abiotic stresses
(Chandrashekhara et al., 2010; Ertani et al., 2013, 2014; Rouphael et al., 2017). The essential oil from Gaultheria procumbens induces SA-mediated defense responses and resistance to Colletotrichum higginsianum in A. thaliana (Vergnes et al., 2014). Nicotiana glutinosa treated with Melaleuca alternifolia (tea tree) oil significantly inhibits lesion development following exposure to TMV (Bishop, 1995). Furthermore, the organic matrix hydrolyte from alfalfa (Medicago sativa L.) increases plant biomass under saline conditions (Ertani et al., 2013).

Global warming is one of the major threats to sustainable agriculture. It is responsible for yield losses and increases the severity of adverse effects of abiotic and biotic stresses during vegetable production. The genus Solanum includes important and diverse vegetable crop species that are grown worldwide. These crops are highly susceptible to the effects of high temperatures, which may disrupt fruit set and cause cellular injuries. Under heat stress conditions, plants activate heat tolerance mechanisms. For example, HSPs are produced to facilitate the refolding of damaged proteins (Wang et al., 2004). Additionally, the defense hormone SA helps mediate the heat stress tolerance of diverse crops (Larkindale et al., 2005; Wang et al., 2010). Exogenous SA reportedly enhances the antioxidant system and promotes APX and glutathione reductase activities to modulate Vitis vinifera thermotolerance (Wang and Li, 2006; Khan et al., 2013). Moreover, the priming of Solanum lycopersicum and Cucumis sativus with SA alleviates damage of heat stress through upregulating HSP70 and HSF expression levels (Snyman and Cronje, 2008) or increasing the maximum quantum yield of photosystem II (Shi et al., 2006).

Elevated temperatures interfere with plant physiological processes, and can also inhibit the resistance to pathogenic viruses. A previous study confirmed that high temperatures suppress the TSWV-mediated HR of Capsicum annuum (Moury et al., 1998). Another study revealed high temperatures decrease the abundance of the $\mathrm{N}$ protein responsible for resistance of Nicotiana tabacum to TMV (Zhu et al., 2010). Additionally, viral infections decrease plant tolerance to high temperatures, as suggested by the downregulated transcription and translation of heat-inducible genes in tomato plants infected by TYLCV (Anfoka et al., 2016).

Tomato yellow curl viruses are the most devastating viral pathogens infecting tomato plants (Varma and Malathi, 2003). TYLCTHV, is a bipartite begomovirus (family Geminiviridae), mainly transmitted by Bemisia tabaci biotype B, and it has been the predominant tomato-infecting begomovirus in Taiwan since 2007 (Tsai et al., 2011; Weng et al., 2015). In tomato plants, the overexpression of Solanum lycopersicum mitogen-activated protein kinase 3 (SlMPK3) upregulates the expression of SA/JAmediated defense-related genes (e.g., pathogenesis-related gene 1 (PR1), PR1b/ leucine aminopeptidase A (SlLapA), proteinase inhibitor I-I (SlPI-I), and SlPI-II) to enhance their resistance to TYLCV (Li et al., 2017). The application of exogenous SA and MeJA on tomato leaves can significantly induce SlMPK3 expression to mediate defense response mechanisms (Yi et al., 2015). Moreover, SA and JA inhibit viral replication as well as cell-to-cell and long-distance viral movements (Shang et al., 2011; Faoro and Gozzo, 2015). 
Both SA-mediated defense and RNA silencing are involved in resistance to TYLCV ( $\mathrm{Li}$ et al., 2018). RNA silencing is an important antiviral mechanism in plants (Burgyan and Havelda, 2011; Calil and Fontes, 2017; Mäkinen et al., 2017). Long doublestranded RNAs, the triggers of RNA silencing, are processed by Dicer-like (DCL) proteins generating vsiRNAs, the guide strand of which is loaded into Argonaute-containing silencing complexes to initiate specific viral RNA degradation (Hedil and Kormelink, 2016). SlDCL2/SlDCL4-silenced tomato plants show reduced resistance to TYLCV (Li et al., 2018). AGO2 mediates RNA silencing antiviral defenses against the potato viruses potato virus $X$ (Jaubert et al., 2011) and bamboo mosaic virus (Alazem et al., 2017).

Hormone-based defenses against heat stress and viruses have been observed in diverse plant species. However, there is some controversy regarding the strategy of applying synthetic hormones (e.g., SA) to protect plants from various stresses. Although synthetic SA enhances plant defense responses against stresses, it is also detrimental for plant development (Sun et al., 2015). As an alternative, an environmentally friendly antiviral agent, eugenol, was evaluated to increase the resistance of tomato plants to TYLCV (Wang and Fan, 2014; Sun et al., 2016). The application of eugenol increased SA contents and upregulated SlPer1 expression (Sun et al., 2016). Unfortunately, there is a lack of information regarding the development of alternative natural priming agents effective against heat stress and viruses. To the best of our knowledge, different plant species have similar defense mechanisms for mitigating the effects of abiotic and biotic stresses. In this study, we evaluated heat tolerance of tomato plants treated with natural priming agents, and subsequently the resistance of these tomato plants to TYLCTHV was assessed. The agent-induced defense mechanism in tomato plants was also studied.

\section{MATERIALS AND METHODS}

\section{Application of Natural and Synthetic Chemicals}

Eugenol was purchased from Sigma-Aldrich (St. Louis, MO, United States). Anise oil was derived from a commercial product (Taiwan Tekho Fine-Chem, Co., Ltd.). The final reagent concentration and treatment of plants were based on a previously described procedure (Wang and Fan, 2014). The abaxial surface of tomato leaves were evenly sprayed with $200 \mu \mathrm{g} \mathrm{mL}^{-1}$ eugenol or anise oil which was prepared in $0.05 \%$ Tween 80 (control solution) $24 \mathrm{~h}$ before inoculation with TYLCTHV.

\section{Plant Materials}

Tomato (Solanum lycopersicum L.) cultivar 'Know-You 301' was used in this study. Seeds were surface-sterilized with $0.5 \% \mathrm{NaClO}$ for $5 \mathrm{~min}$ and then washed with distilled water. Seeds were germinated and grown in a greenhouse at $25^{\circ} \mathrm{C}$ with a 12 -h light/12-h dark photoperiod. Tomato seedlings approximately $10 \mathrm{~cm}$ tall with 3-5 true leaves (around 14 days after sowing) were used for thermotolerance and virus transmission assays. Seedlings at the 4-true-leaf stage were exposed to viruliferous whiteflies for TYLCTHV inoculation in order to investigate virus infection and accumulation. Each experiment was completed with at least three independent biological replicates.

\section{Ion Leakage and Phenotypic Analysis in Thermotolerance Assays}

The heat tolerance of tomato plants was determined based on the seedling survival rate, average fresh weight, and the results of an ion leakage assay. Specifically, 12-day-old tomato seedlings were individually sprayed with a control solution, anise oil and eugenol three times per day. At $8 \mathrm{~h}$ after the last spray treatment, seedlings were exposed to heat stress at $45^{\circ} \mathrm{C}$ for $12 \mathrm{~h}$. The survival rate and average fresh weight were recorded 5 days later. To evaluate membrane stability, the harvested leaves were subjected to a leakage assay 3 days after heat treatment, which was conducted according to a modified version of a previously described method (Camejo et al., 2005). Leaves were collected and washed three times with deionized water to eliminate any external residues. Samples were placed in glass tubes with $20 \mathrm{ml}$ of de-ionized water and left in the dark at $25^{\circ} \mathrm{C}$ for $20 \mathrm{~h}$. Then, the conductivity values (C1) of aqueous solutions were examined immediately with a conductivity meter (SUNTEX SC-170, Suntex Instruments, Co., Ltd., Taipei, Taiwan) Subsequently, the sample was autoclaved at $121^{\circ} \mathrm{C}$ for $30 \mathrm{~min}$ in order to kill the tissues and then the conductivity (C2) of this solution was recorded. The percentage of electrolytes was calculated as follows: electrolyte $(\%)=\mathrm{C} 1 / \mathrm{C} 2 \times 100$.

\section{TYLCTHV Infection}

Tomato yellow leaf curl Thailand virus isolate LY5 (GenBank Accession No. GU723742) was provided by The World Vegetable Center (Tainan, Taiwan), and was maintained on tomato cultivar 'ANT22' via whitefly-mediated transmission. Bemisia tabaci B biotype laboratory colonies (with mtCO1 sequences that are identical to GenBank Accession No. EU4 27726) were derived from individuals collected from poinsettia (Euphorbia pulcherrima) plants grown in fields in Hualien City, Taiwan. The colonies were maintained on Chinese kale (Brassica oleracea) in whitefly-proof cages at $28^{\circ} \mathrm{C}$ with a 14 -h light/10-h dark photoperiod. For each whitefly biotype, colony purity was monitored every five generations with a PCR assay using biotypespecific primers (Ko et al., 2007). Whiteflies, especially the B. tabaci B biotype, transmit TYLCTHV with an efficiency of 80\% after an 8-h AAP (Weng et al., 2015). In the current study, adult whiteflies were provided a 48 -h AAP. The abaxial surfaces of tomato leaves were evenly sprayed with $200 \mu \mathrm{g} \mathrm{mL}^{-1}$ eugenol or anise oil $24 \mathrm{~h}$ before two potentially viruliferous whiteflies were transferred to each tomato seedling. The whiteflies were enclosed in a small net bag $(6 \mathrm{~cm} \times 15 \mathrm{~cm}, 110$ mesh) with a leaf for a 48-h IAP (Supplementary Figure S1A). Fifteen replicates were inoculated. After the IAP, the whiteflies were removed from the plants, which were then treated with a systemic insecticide (acetamiprid, 1:1500 dilution) to kill any remaining insects. 


\section{Virus Identification and Quantification in Tomato Plants}

To analyze the relationship between TYLCTHV DNA abundance and plant susceptibility, the disease incidence and TYLCTHV genomic DNA content were analyzed. The $2^{\text {nd }}$ leaves of seedlings at the four-true-leaf stage were exposed to viruliferous whiteflies for $48 \mathrm{~h}$ of IAP. Then, the $3^{\text {rd }}$ leaves were collected 0,5 , 10 , and 15 days after the IAP for DNA extraction analysis from three seedlings (Supplementary Figure S1A). A PCR assay was used to assess TYLCTHV infection of plants at 15 days after the 48-h IAP. The TYLCTHV-specific primer set [THAV3 (5'-CCACATCGTCTTYGTTCTG-3') and THAC3 (5'CTTAAYYTTRATATTYTCATCCATCCA- $\left.3^{\prime}\right)$ ] was used and a previously described PCR protocol (Rojas et al., 1993). The expected size of the amplified product was $1,516 \mathrm{bp}$. The relative TYLCTHV DNA-A (GU723742.1) and DNA-B (GU723754.1) expression levels were determined by quantitative PCR. The qPCR assay was done with the Power SYBR Green Master Mix (Life Technologies, Carlsbad, CA, United States), gene-specific primer sets (Supplementary Table S1), and the QuantStudio 3 system (Life Technologies). The qPCR program was as follows: $95^{\circ} \mathrm{C}$ for $5 \mathrm{~min} ; 40$ cycles of $95^{\circ} \mathrm{C}$ for $10 \mathrm{~s}, 58^{\circ} \mathrm{C}$ for $15 \mathrm{~s}$, and $72^{\circ} \mathrm{C}$ for $20 \mathrm{~s}$. The annealing temperature was modified depending on the melting temperature of each primer set, and each reaction was repeated at least three times. GAPDH was used as internal controls for calculating relative DNA amounts. Relative TYLCTHV DNA contents were normalized against tomato plants at $0 \mathrm{dpi}$. The $\mathrm{qPCR}$ data were analyzed using the $2^{-\Delta \Delta \mathrm{Ct}}$ method.

\section{Gene Expression Analysis}

The effects of anise oil and eugenol on the transcript levels of defense-related genes in tomato were examined by RT-qPCR. The following genes were analyzed: TYLCTHV genes, $A C 1$ and $B C 1$; heat-related genes, heat stress transcription factor A2 (SlHSFA2), SlHSFB1, heat shock protein101 (SlHSP101), SlHSP90, and SlHSP17.6; antioxidants genes, ascorbate peroxidase 2 (SlAPX2) and catalase 2 (SlCAT2); SA-related defense genes, SIPR1, SlPR1b, non expressor of PR1 (SlNPR1), alternative oxidase 1a (SlAOX1a), and SlAOX1c; RNA silencing genes, SlDCL2, SlDCL4, SlAGO1A, SlAGO1B, SlAGO2A, SlAGO2B, SlRDR1, and Ty-1; and JA-related defense genes, SIPI-II, polyphenol oxidase (SlPPO), lipoxygenase D (SlLoxD), SlMAPK3, and coronatine-insensitive 1 (SlCOI1). RT-qPCR primer sets are listed in Supplementary Table S2. Experiments were conducted in a growth chamber set at $25^{\circ} \mathrm{C}$ with a 16 -h light $/ 8$-h dark photoperiod and $80 \%$ relative humidity. Plant samples were collected at 0,8 , and $24 \mathrm{~h}$ after the treatments with anise oil, eugenol, or control solution. Total RNA was extracted with TRIzol Reagent (Thermo Fisher Scientific, Waltham, MA, United States) according to the manufacturer's instructions. The RNA was then reverse transcribed with M-MLV Reverse Transcriptase (Thermo Fisher Scientific), and the resulting cDNA was amplified by $\mathrm{qPCR}$ using primer sets shown in Supplementary Table S2. The qPCR program was as follows: $95^{\circ} \mathrm{C}$ for $5 \mathrm{~min} ; 40$ cycles of $95^{\circ} \mathrm{C}$ for $10 \mathrm{~s}, 60^{\circ} \mathrm{C}$ for $15 \mathrm{~s}$, and $72^{\circ} \mathrm{C}$ for $20 \mathrm{~s}$. The annealing temperature was modified depending on the melting temperature of each primer set, and each reaction was repeated at least three times. The $\beta$-actin (NM_001330119.1) expression level was used as an internal control. Relative gene expression levels were normalized against the gene expression levels in untreated plants or plants treated with control solution. Data were analyzed with the $2^{-\Delta \Delta \mathrm{Ct}}$ method.

\section{Determination of Salicylic Acid and Jasmonic Acid Contents}

The total SA and JA contents in tomato leaves were determined with the Plant SA ELISA kit (\#MBS9314138) and Plant JA ELISA kit (\#MBS9315634) (MyBioSource, San Diego, CA, United States), respectively. Harvested leaf tissues (approximately $0.1 \mathrm{~g}$ ) were ground to a fine powder in liquid nitrogen and then mixed with $1 \mathrm{~mL}$ PBS $(10 \mathrm{mM}$ phosphate buffer, $\mathrm{pH}$ $7.4,150 \mathrm{mM} \mathrm{NaCl})$. Samples were centrifuged $(1,000 \times g$ for $20 \mathrm{~min}$ at $25^{\circ} \mathrm{C}$ ), after which a $50-\mu \mathrm{L}$ aliquot of the supernatant was loaded into the wells of a 96-well plate (MyBioSource, San Diego, CA, United States). To quantify the SA content, wells were prepared with one of six standard concentrations (ranging from 0.5 to $16 \mu \mathrm{g} \mathrm{mL}^{-1}$ ). To quantify the JA content, wells were prepared with one of six standard concentrations (ranging from 0.25 to $8 \mathrm{nM}$ ). Other than the different standard concentrations, the SA and JA contents were measured using the same procedure. After adding the horseradish peroxidaseconjugated reagent to each well, the plate was incubated at $37^{\circ} \mathrm{C}$ for $1 \mathrm{~h}$, after which each well was washed four times with washing buffer. The optical density $(450 \mathrm{~nm})$ of each well was measured with an ELISA reader within 15 min after adding Stop Solution. Relative SA and JA levels were normalized against those levels in untreated tomato plants.

\section{Determination of Reactive Oxygen Species Content by Histochemical Staining}

$\mathrm{H}_{2} \mathrm{O}_{2}$ content in tomato leaves was determined with 3,3diaminobenzidine (DAB, Sigma-Aldrich) as a substrate (OrozcoCardenas and Ryan, 1999). Each detection was done in triplicate with 10 seedling plants for each repeat. The upper leaves of seedlings at the four-true-leaf stage were excised and treated with $1 \mathrm{mg} / \mathrm{mL} \mathrm{DAB}$ solution $(\mathrm{pH} 3.8$ ) via an incision. The treated leaves were incubated at $25^{\circ} \mathrm{C}$ for $20 \mathrm{~h}$ in dark. The leaves were then decolorized in a boiling solution of 3:1:1 ethanol: lactic acid: glycerol. After cooling, leaves were submerged in the same solution and photographed under a light microscope. In addition, $\mathrm{H}_{2} \mathrm{O}_{2}$ content was also quantified by titanium chloride method as described by Jana and Choudhuri (1982).

\section{Data Analysis}

All data were analyzed with Student's $t$-test in the SPSS program (version 18.0.0) (IBM, Corp., Armonk, NY, United States). For multiple comparisons, Fisher's least significant difference test (LSD) was performed on all data after ANOVA when significant differences $(P<0.05)$ were detected among different 
A

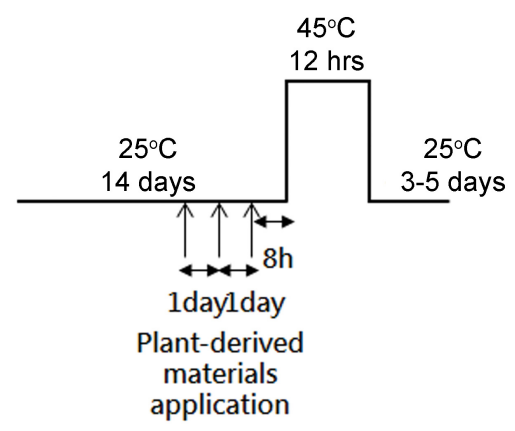

B

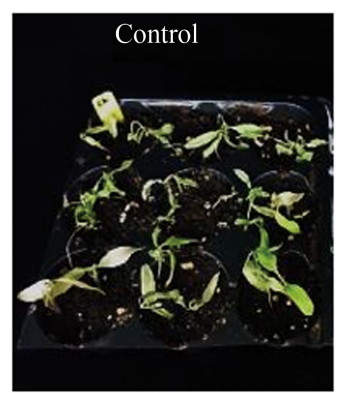

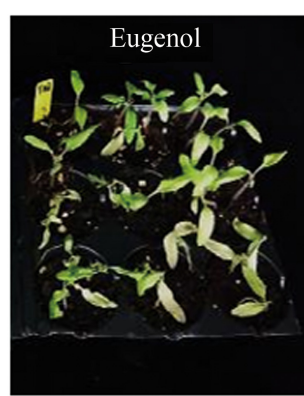

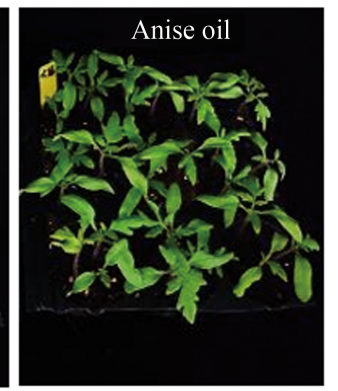

C

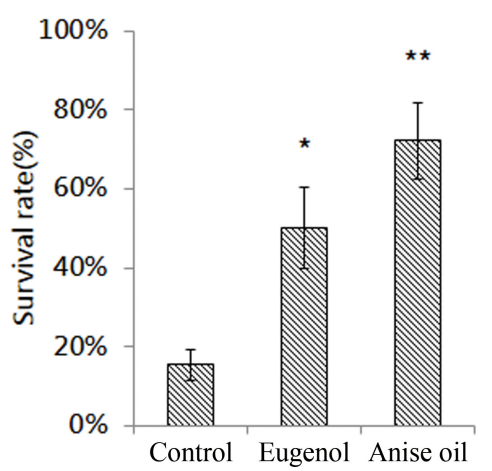

D

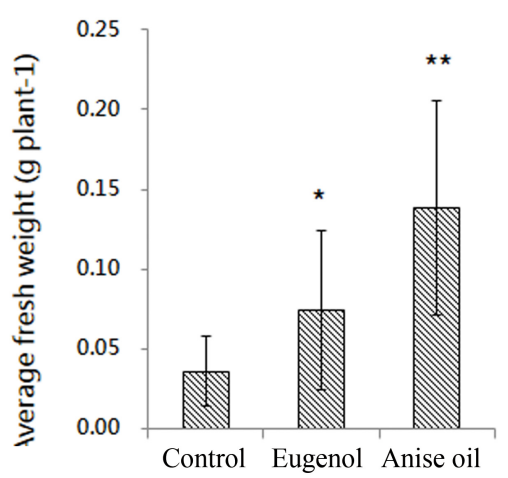

E

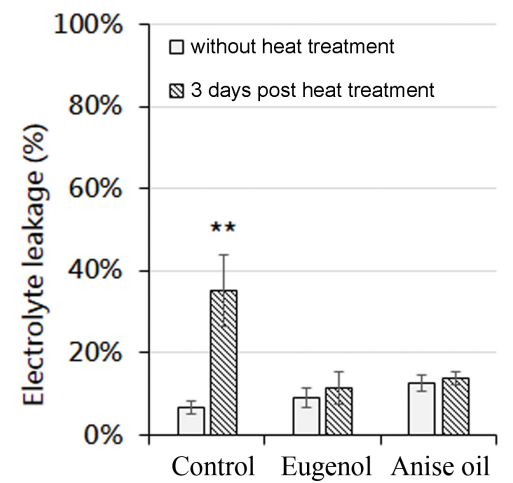

FIGURE 1 | Effects of the pre-application of eugenol and anise oil on the thermotolerance of tomato plants. (A) Schedule for the application of plant-derived materials, heat treatment, and harvest. Phenotypes were analyzed at the indicated time points. The concentrations of the plant-derived materials, eugenol and anise oil, were $200 \mu \mathrm{g} \mathrm{mL}^{-1}$. After an exposure to heat stress and a 5-day recovery period, tomato plants with different treatments were photographed (B). The survival rates $\mathbf{( C )}$ and fresh weights (D) of these plants were also recorded based on 18 technical replicates in three independent experiments. Additionally, the relative leakage of leaf electrolytes (E) was measured after a 3-day recovery period. Bars represent the mean of three experiments ( \pm standard error of the mean). Significant differences between control and anise oil- or eugenol-treated plants were assessed with Student's $t$-test $\left({ }^{*} P<0.05 ;{ }^{* *} P<0.01\right)$.

treatments. Each experiment was completed with at least three replicates.

\section{RESULTS}

\section{Effects of Eugenol and Anise Oil on the Thermotolerance of Tomato Plants}

Several natural chemicals and synthetic agents have been reported to directly or indirectly influence plants that are exposed to environmental stresses. To assess the effects of eugenol and anise oil on tomato seedlings under heat stress conditions, 12day-old tomato seedlings were sprayed with control solution, eugenol $\left(200 \mu \mathrm{g} \mathrm{mL}^{-1}\right)$, or anise oil $\left(200 \mu \mathrm{g} \mathrm{mL}^{-1}\right)$ three times daily. At $8 \mathrm{~h}$ after the final spray treatment, plants were subjected to heat stress at $45^{\circ} \mathrm{C}$ for $12 \mathrm{~h}$ (Figure 1A). After a 3- or 5day recovery period at $25^{\circ} \mathrm{C}$, the phenotypes, survival rates, and average fresh weights were recorded (Figures 1B-D). Plants treated with eugenol or anise oil grew well after the heat treatment and 5-day recovery period, particularly those treated with anise oil (Figure 1B). In contrast, control plants exhibited significant wilting and yellowing of leaves (Figure 1B). Additionally, the survival rates (Figure 1C) and average fresh weights (Figure 1D) were significantly greater for the eugenol- and anise oil-treated plants than the control. Without heat treatment, the plants treated with eugenol, anise oil and control solution showed similar healthy phenotypes (Supplementary Figure S1B).

A previous study has reported that heat alters membrane fluidity and lipid peroxidation and also impairs membrane selectivity (Dias et al., 2010). To assess whether the priming agents affected membrane stability, electrolyte leakage was analyzed for untreated $\left(25^{\circ} \mathrm{C}\right)$ and heat-treated plants after a 3 day recovery period. Electrolyte leakage was significantly lower in eugenol- and anise oil-treated plants than control (Figure 1E). These results suggest that eugenol and anise oil treatments inhibit electrolyte leakage in tomato plants.

Heat shock proteins and HSFs are considered the central components of heat stress response in plants (Nover and Scharf, 1997; Kotak et al., 2007). Thus, SlHSFA2, SlHSFB1, SlHSP101, SlHSP90, and SlHSP17.6 were analyzed by RT-qPCR (Figure 2); 12-day-old tomato seedlings sprayed with control solution, eugenol $\left(200 \mu \mathrm{g} \mathrm{mL}^{-1}\right)$, or anise oil $\left(200 \mu \mathrm{g} \mathrm{mL}^{-1}\right)$ three times daily were incubated at $45^{\circ} \mathrm{C}$ for $12 \mathrm{~h}$ (Figure 2A). After heat treatment $(0 \mathrm{hpt})$ and 8 -h recovery $(8 \mathrm{hpt})$, total 


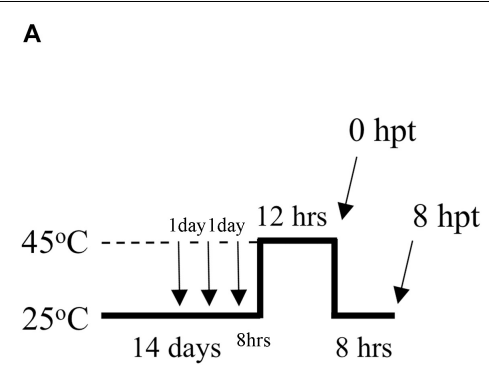

D

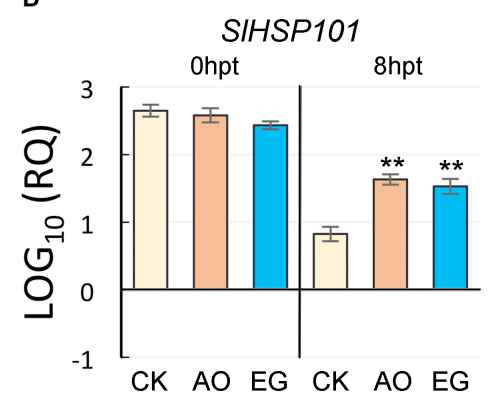

B

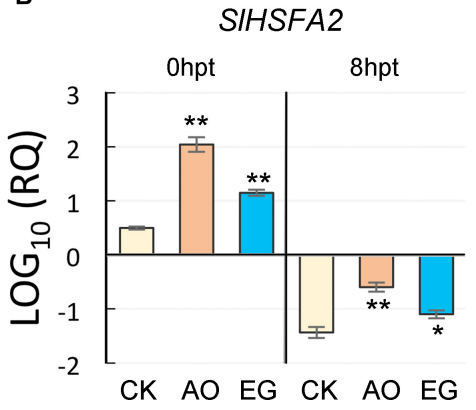

E

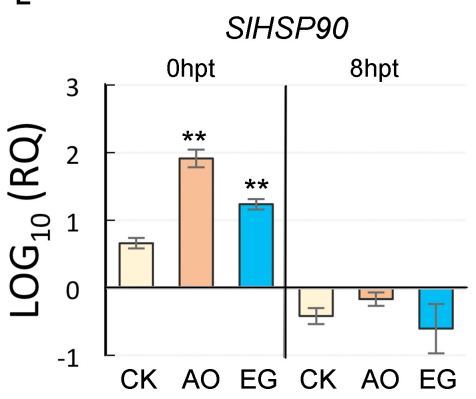

C

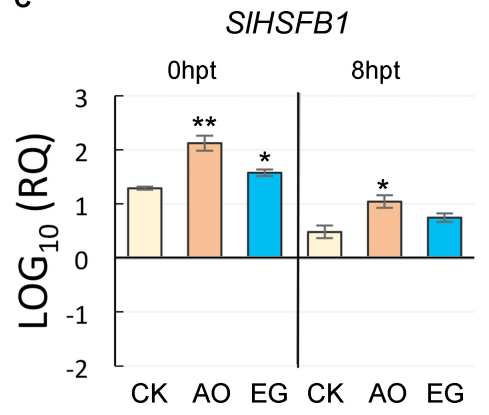

FIGURE 2 | Effects of anise oil and eugenol on the expression of HSFs and HSPs in tomato plants under heat stress. Fourteen-day-old tomato seedlings treated with a control solution (CK), anise oil (AO), or eugenol (EG) for $24 \mathrm{~h}$ were subjected to heat stress at $45^{\circ} \mathrm{C}$ for $12 \mathrm{~h}$. After heat treatment (0 hpt) and 8 -h recovery (8 hpt), total RNA was extracted from these plants (A). The SIHSFA2 (B), SIHSFB1 (C), SIHSP101 (D), SIHSP90 (E), and SIHSP17.6 (F) expression levels were analyzed by RT-qPCR. The $\beta$-actin expression level was used as the internal control. Relative gene expression levels were normalized against the expression level in untreated tomato plants. Data were analyzed with the $2^{-\Delta \Delta \mathrm{Ct}}$ method. Bars represent the mean ( \pm standard error of the mean) of three independent biological replicates each with three technical replicates. Significant differences between control and anise oil- or eugenol-treated plants were assessed with Student's $t$-test $\left({ }^{*} P<0.05 ;{ }^{*} P<0.01\right)$

RNA from those seedlings was isolated and analyzed. At 0 hpt, SlHSFA2, SlHSFB1, SlHSP90, and SlHSP17.6 were significantly increased in anise oil- and eugenol-treated plants compared to the control (Figures 2B,C,E,F). At $8 \mathrm{hpt}$, the expression levels of SlHSP101 and SlHSP17.6 were significantly higher in anise oil- and eugenol-treated plants than in the control (Figures 2D,F). This suggests that eugenol and anise oil regulate the expression of HSF and HSP genes under heat stress. In addition, the expression of genes in the RNA silencing pathway and antioxidant was also analyzed (Supplementary Figure S2). The expression levels of SIDCL2 and SIAPX2 were significantly higher in anise oil- and eugenol-treated plants than in the control at $8 \mathrm{hpt}$ (Supplementary Figures S2B,D), while the expression of SlAGO2A, SlDCL4, and SlCAT2 did not significantly differ among plants irrespective of the treatments (Supplementary Figures S2A,C,E). Taken together, these results suggest that priming tomato plants with eugenol or anise oil enhances thermotolerance in plants.

\section{Exogenous Application of Anise Oil and Eugenol Increased the Resistance of Tomato Plants Against TYLCTHV}

Several studies have indicated that heat stress and TYLCV infection can induce similar responses in plants
(Clarke et al., 2004, 2009; Anfoka et al., 2016; Li et al., 2017). Since TYLCTHV is one of the predominant begomoviruses infecting tomato in Taiwan, tomato plants were infected with TYLCTHV to verify the similarity between plant responses to heat stress and viral disease. Tomato plants were treated with a foliar application of anise oil or eugenol $24 \mathrm{~h}$ before exposure to viruliferous whiteflies. At 15 days post-inoculation (dpi), only mild symptoms were observed on seedlings treated with anise oil or eugenol (Figure 3A), whereas severe TYLCTHV-induced disease symptoms, such as leaf yellowing, leaf curling, and stunted growth, were observed in control plants (Figure 3A). Disease incidence at $15 \mathrm{dpi}$ was evaluated based on PCR amplification of TYLCTHV sequences. Exogenous application of eugenol (100, 200, and $400 \mu \mathrm{g} \mathrm{mL} \mathrm{mL}^{-1}$ ) significantly decreased disease incidence compared to the control (Figure 3B). Similarly, 100, 200, and $400 \mu \mathrm{g} \mathrm{mL}^{-1}$ anise oil treatments also decreased disease incidence in a concentration-dependent manner (Figure 3B). To calculate the amount of TYLCTHV in infected tissues, a qPCR assay was used, targeting the DNA-A and DNA-B genomic segments (Figures 3C,D). DNA-A and DNA-B levels were substantially higher in the control than in anise oil- and eugenol-treated plants at $10 \mathrm{dpi}$ (Figures 3C,D). Furthermore, although the relative DNA-A abundance was elevated among all treatments, virus accumulation in the control was still 
A

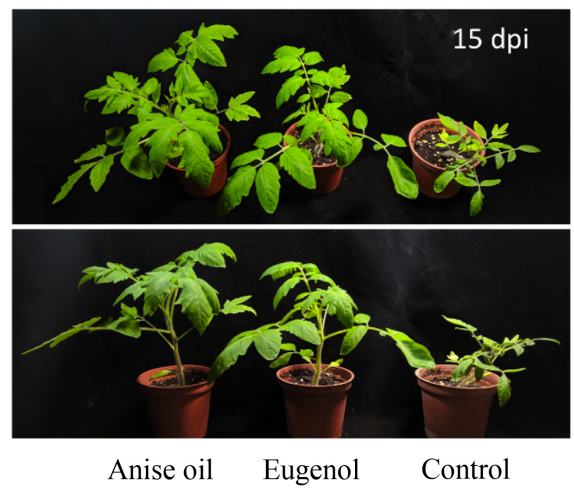

B

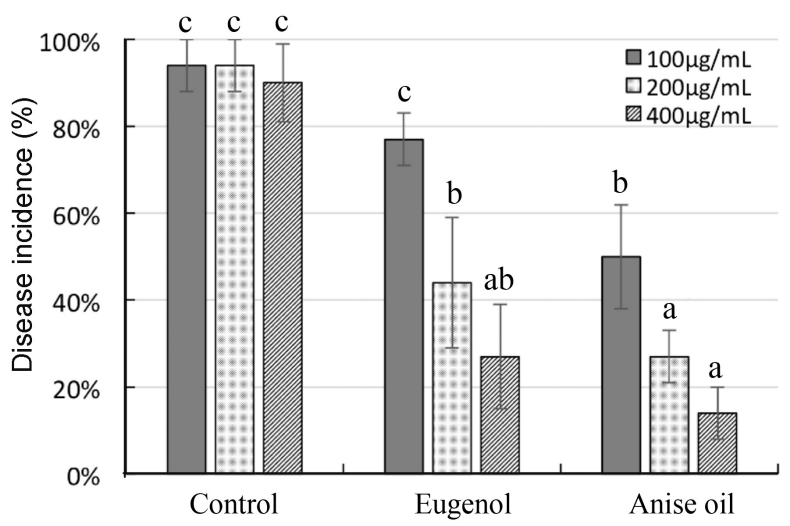

C

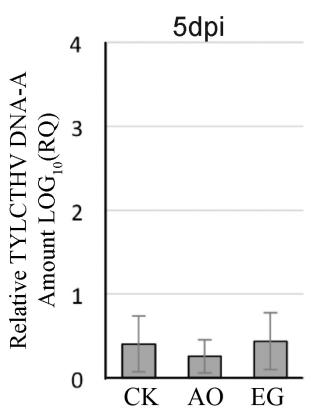

E

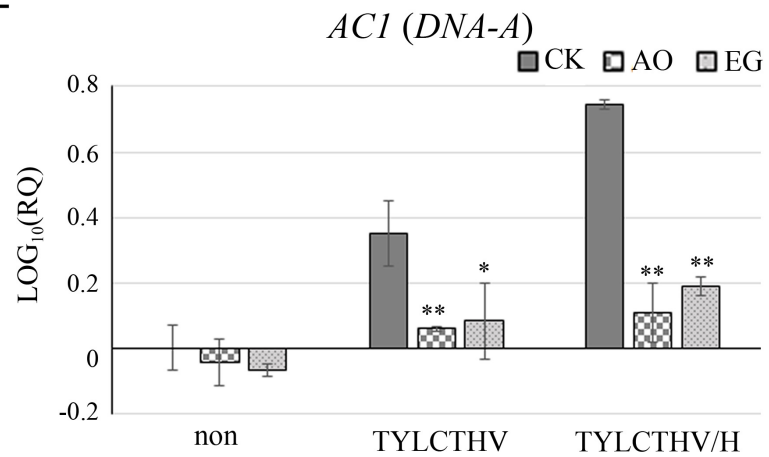

D

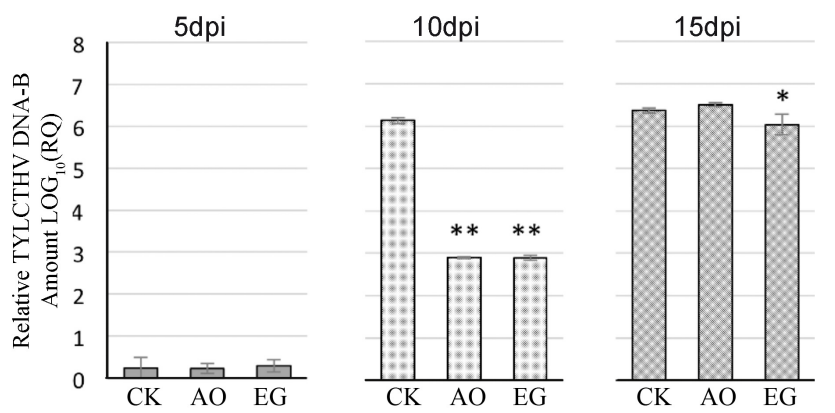

$\mathbf{F}$

$B C 1(D N A-B)$

$\square \mathrm{CK} \square \mathrm{AO} \quad \square \mathrm{EG}$

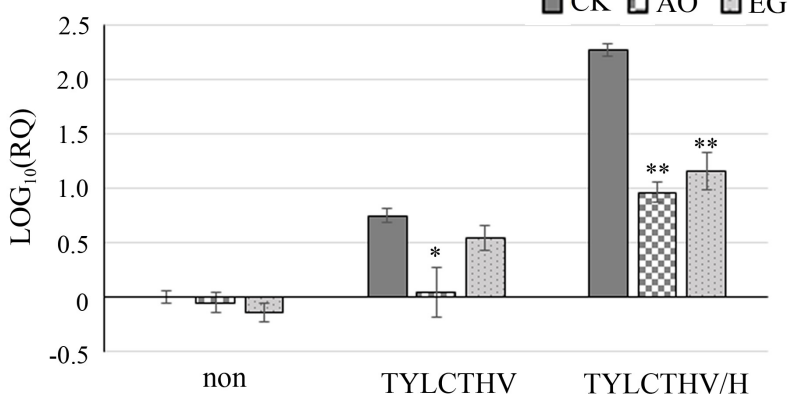

FIGURE 3 | Antiviral effects of anise oil and eugenol on TYLCTHV. Tomato plants were treated with foliar applications of eugenol (100, 200, or $\left.400 \mu \mathrm{g} \mathrm{mL}{ }^{-1}\right)$ or anise oil $\left(100,200\right.$, or $\left.400 \mu \mathrm{gL}^{-1}\right) 24 \mathrm{~h}$ before TYLCTHV inoculations. The plants were photographed at 15 days post-inoculation (dpi) (A). The disease incidence was evaluated by detecting TYLCTHV-positive plants at 15 dpi. Fisher's least significant difference test (LSD) was employed examining significant differences $(P<0.05)$ among different treatments. (B). Additionally, the relative abundances of TYLCTHV DNA-A (C) and DNA-B (D) in anise oil- and eugenol-treated plants and control were estimated by a quantitative real-time PCR assay. Samples were collected every 5 days after the onset of the viral infection ( $0,5,10$, and 15 dpi). Five individual samples for each treatment were analyzed. Relative TYLCTHV DNA amounts in tomato plants were normalized against the DNA content at 0 dpi. In addition, relative expression of viral RNA, $A C 1(\mathbf{E})$ and $B C 1(\mathbf{F})$, at 5 dpi was also analyzed by RT-qPCR. The $\beta$-actin expression level was used as the internal control. Relative gene expression levels were normalized against the expression level in control. Data were analyzed with the $2^{-\Delta \Delta C t}$ method. Bars represent the mean ( \pm standard error of the mean) of at least three independent biological replicates each with three technical replicates. Significant differences between control and anise oil- or eugenol-treated plants were assessed with Student's $t$-test $\left(^{*} P<0.05\right.$; ${ }^{*} P<0.01$ ).

higher than in anise oil- and eugenol-treated plants at 15 dpi (Figure 3C).

To verify that anise oil and eugenol affected the accumulation of TYLCTHV in tomato plants, the expression levels of AC1 (replicase-associated protein) and $B C 1$ (movement protein) were measured by RT-qPCR. $A C 1$ and $B C 1$ are located in DNAA and DNA-B of TYLCTHV, respectively. After TYLCTHV infection, anise oil and eugenol decreased the expression of $A C 1$ and $B C 1$ compared to the control (Figures 3E,F). Moreover, heat stress has been demonstrated to enhance accumulation 
of TYLCV (Anfoka et al., 2016). Anise oil and eugenol also decreased the expression of $A C 1$ and $B C 1$ compared to the control after TYLCTHV infection combined with heat treatment (Figures 3E,F).

\section{Exogenous Application of Anise Oil and Eugenol Upregulated the Expression of Salicylic Acid- and Jasmonic Acid- Mediated Genes}

Since SA and JA enhance plant tolerance to heat and viral infections (Clarke et al., 2004; Shang et al., 2011; Li et al., 2017; Makarova et al., 2018), we measured the expression level of selected SA- and JA-related genes in anise oil- and eugenoltreated plants (Figure 4). The RT-qPCR results revealed that the expression levels of the SA-associated genes, SlPR1, SIPR1b, SINPR1, SlAOX1a, and SIAOX1c, were significantly upregulated in eugenol and anise oil treatment compared to the control at 8 or $24 \mathrm{hpt}$ (Figures 4B-F). Additionally, the expression levels of the JA-associated genes, SIPI-II, SIPPO, SlLoxD, and SlCOI1, were also strongly upregulated in the plants treated with anise oil or eugenol compared to the control at 8 or 24 hpt (Figures $4 \mathbf{G}-\mathbf{K}$ ). The expression of SlMPK3 did not significantly differ among plants irrespective of the treatments (Figure 4I). Overall, eugenol and anise oil significantly increased the expression of a few SA- and JA-related genes to modulate stress responses.

\section{Exogenous Application of Anise Oil and Eugenol Upregulated the Expression of Genes for RNA Silencing Machinery}

To elucidate if exogenous application of anise oil and eugenol influences genes involved in RNA silencing machinery, genes reported to be involved in the RNA silencing response against TYLCV were analyzed. SlDCL2/SlDCL4-silenced tomato plants were shown to be less resistant against TYLCV (Li et al., 2018). Ty-1/Ty-3, a DFDGD-Class RNAdependent RNA polymerase (RDR), mediates resistance against TYLCV (Verlaan et al., 2013; Butterbach et al., 2014). Hence, the analysis was focused on the gene expression levels of SIDCL2, SIDCL4, and Ty-1 (Figures 5A-C). At 24 hpt, SIDCL2 and SIDCL4 transcript levels were higher in anise oil and eugenol treatments compared to the control (Figures 5A,B). At $8 \mathrm{hpt}$, SlDCL2 transcript levels were also higher in anise oil and eugenol treatments compared to the control, whereas SIDCL4 transcript levels were higher only in eugenol-treated plants (Figures 5A,B). In case of Ty-1, transcript levels showed a slight increase after anise oil and eugenol treatments compared to the control at $8 \mathrm{hpt}$; conversely, the transcripts showed no significant differences among all treatments at $24 \mathrm{hpt}$ (Figure 5C). The expression of other genes in the RNA silencing pathway was also analyzed (Figures 5D-H). SlAGO1A, SlAGO1B, and $S l A G O 2 B$, transcript levels were not altered at 8 or 24 hpt in all treatments (Figures 5E,G,H). Only SlAGO2A and SlRDR1 transcripts showed significant increases at $8 \mathrm{hpt}$ (Figures 5D,F). Therefore, these results reveal that eugenol and anise oil may act as priming agents to up-regulate specific RNA silencing pathway genes.

\section{Exogenous Application of Anise Oil and Eugenol Altered the Transcriptional Activity of TYLCTHV and Expression of Defense Genes Under Stress}

Anise oil and eugenol can affect the expression levels of some of SA-, JA-, and RNA silencing pathway genes (Figures 4, 5). Therefore, some defense-related genes were also analyzed for the effect of TYLCTHV infection with/without heat stress (Figure 6). The results showed that the expression levels of SIPR1and SIPR1b were significantly higher after anise oil and eugenol treatments under TYLCTHV/heat stress (Figures 6A,B). SlAOX1a expression was upregulated by anise oil and eugenol under TYLCTHV infection compared to the control (Figure 6D). In addition, SIPI-II was also increased by TYLCTHV infection and TYLCTHV/heat stress (Figure 6J). Ty1 was upregulated under TYLCTHV/heat stress by eugenol treatment and was upregulated under TYLCTHV infection by anise oil treatment (Figure 6H). With TYLCTHV infection and TYLCTHV/heat stress, the expression levels of SINPR1, SIDCL2, SIDCL4, and $S I M P K 3$ showed no significant differences among anise oil, eugenol and control (Figures 6C,E,F,I). These results suggest that genes, such as SlPR1, SlPR1b, and SlPI-II, were upregulated in anise oil- and eugenol-treated plants during both priming (Figures $4 \mathbf{B}, \mathbf{C}, \mathbf{G}$ ) and stresses-induced states (Figures $\mathbf{6 A}, \mathbf{B}, \mathbf{J}$ ). Moreover, plants pre-treated with anise oil and eugenol resisted TYLCTHV infection under normal temperature and heat stress. Therefore, these results suggest that anise oil- and eugenol-treated plants may regulate a number of defense genes to mediate TYLCTHV resistance.

\section{Exogenous Application of Anise Oil and Eugenol Modulated the Endogenous Salicylic Acid and Jasmonic Acid Contents in Unstressed Tomato Plants}

To determine whether endogenous SA and JA contents correspond to the expression patterns of SA- and JA-mediated genes, we examined the endogenous SA and JA contents in tomato plants sprayed with control solution, eugenol, or anise oil. Both SA (Figure 7A) and JA (Figure 7B) levels increased significantly in anise oil- and eugenol-treated plants compared to the control. TYLCV infections are usually accompanied by heat stress in agricultural systems (Czosnek, 2007). Heat also aggravated TYLCV accumulation in plants after TYLCV infection (Anfoka et al., 2016). Hence, the endogenous SA and JA contents were also examined in tomato plants treated with heat and TYLCTHV/heat. Under these stresses, the endogenous SA and JA contents showed no significant difference between control, eugenol, and anise oil treatments (Supplementary Figures S3A,B). Overall, these results suggest that eugenol and anise oil may have some 


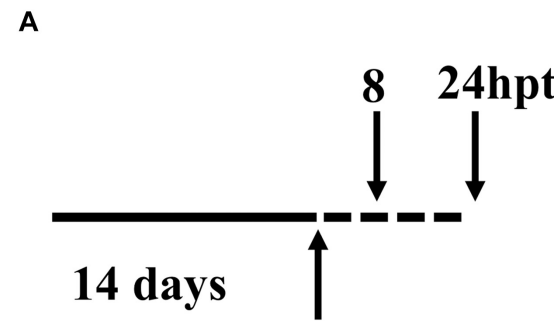

\section{Plant-derived materials treatments}

D

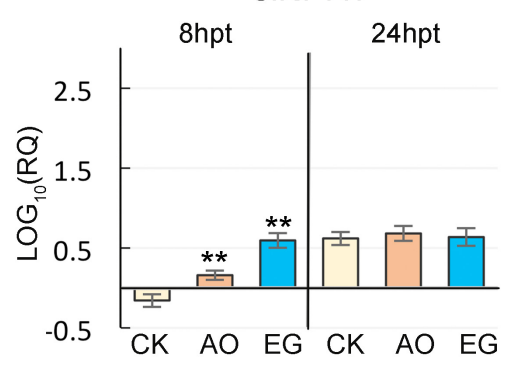

B

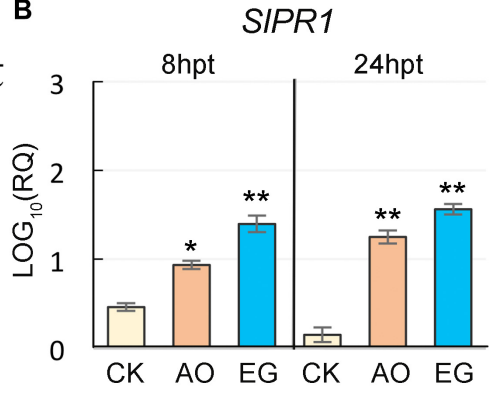

C

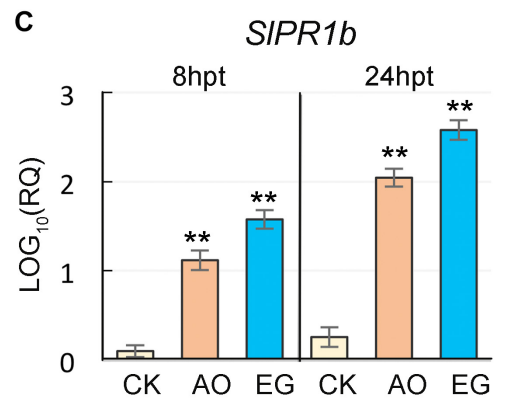

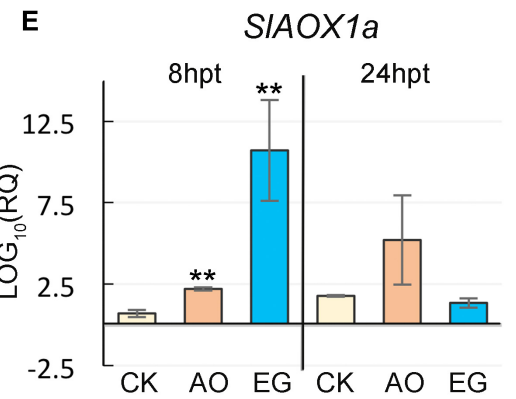

$\mathbf{F}$ SIAOX1C

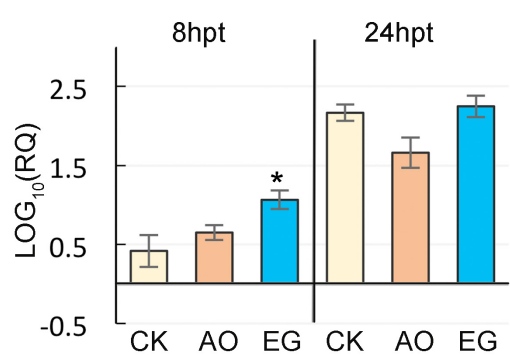

G

SIPI-II

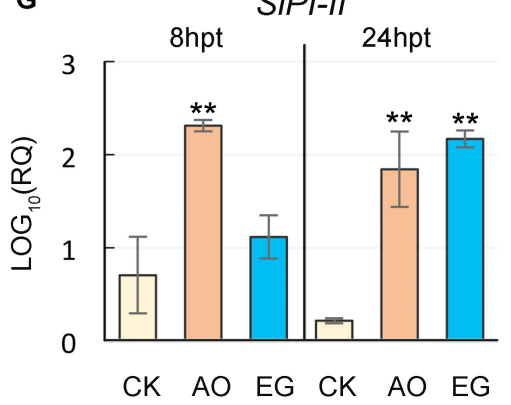

H

SIPPO

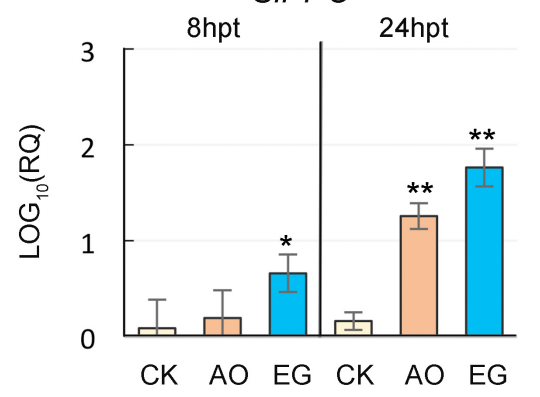

I

SIMPK3

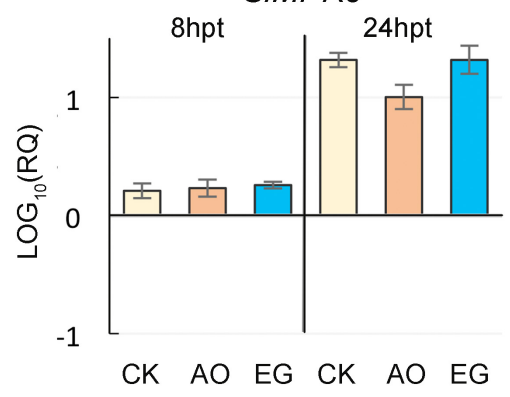

J

SILOXD
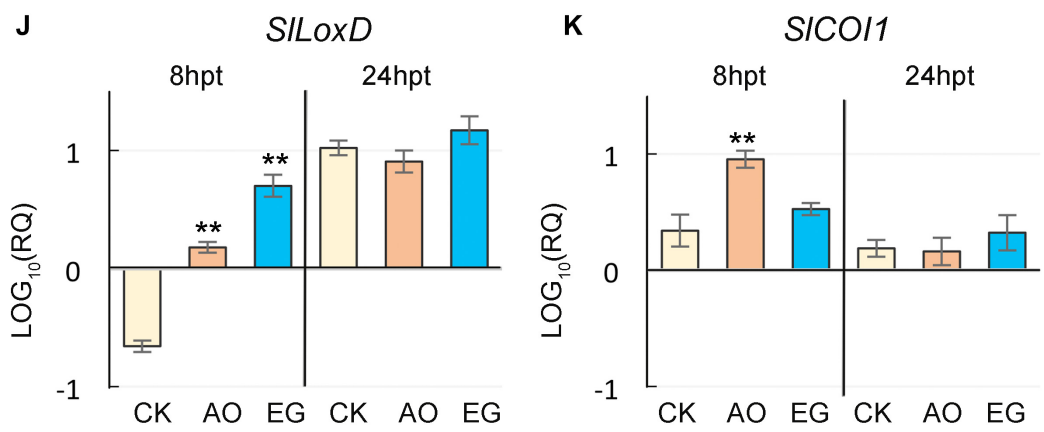

FIGURE 4 | Effects of anise oil and eugenol on the expression of SA- and JA-related genes in tomato plants. Fourteen-day-old tomato seedlings were treated with a control solution (CK), anise oil (AO), or eugenol (EG). Total RNA was extracted from these plants at $8 \mathrm{~h}$ post-treatment (hpt) and $24 \mathrm{hpt}$ (A). The expression levels of SA-related defense genes, SIPR1 (B), SIPR1b (C), SINPR1 (D), SIAOX1a (E), and SIAOX1C (F), and JA-related defense genes, SIPI-II (G), SIPPO (H), SIMAPK3 (I), SILOXD (J), and SICO/1 (K), were analyzed by qRT-PCR. The $\beta$-actin expression level was used as the internal control. Relative gene expression levels were normalized against the expression level in untreated tomato plants. Data were analyzed with the $2^{-\Delta \Delta \mathrm{Ct}}$ method. Bars represent the mean ( \pm standard error of the mean) of three independent biological replicates each with three technical replicates. Significant differences between control and anise oil- or eugenol-treated plants were assessed with Student's t-test $\left({ }^{*} P<0.05 ; * * P<0.01\right)$. 
A

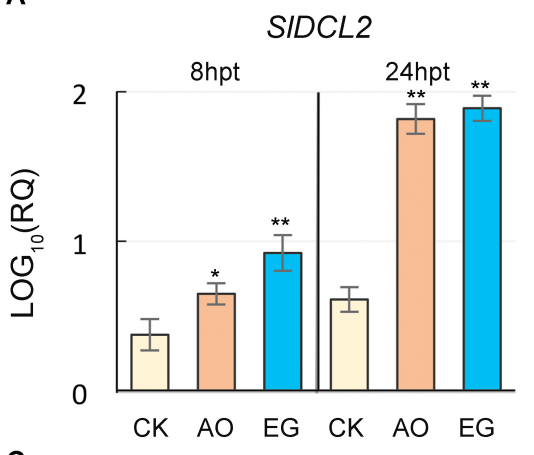

C
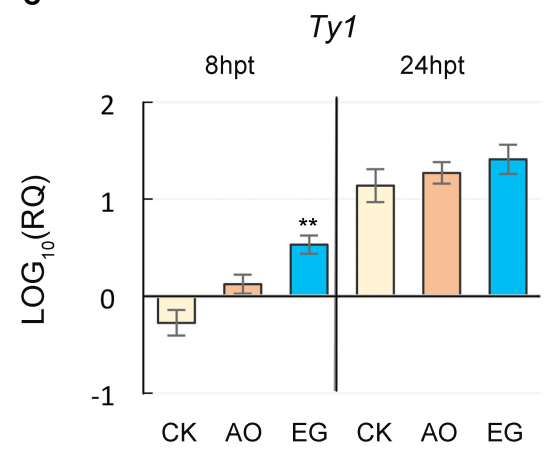

E

SIAG01A

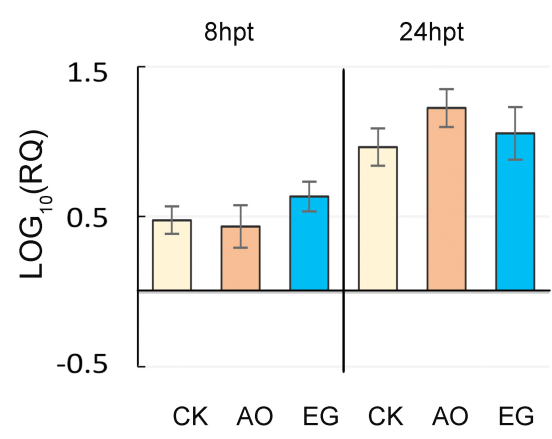

G

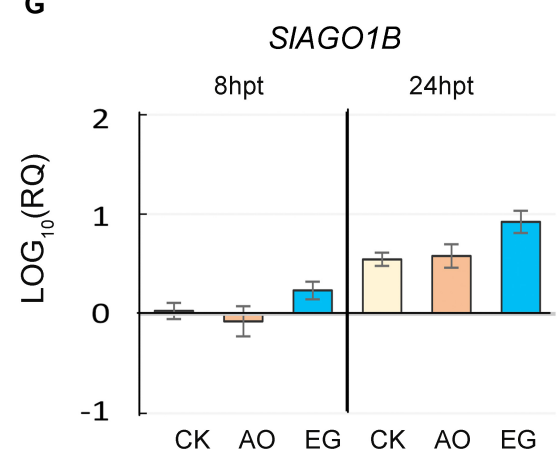

B
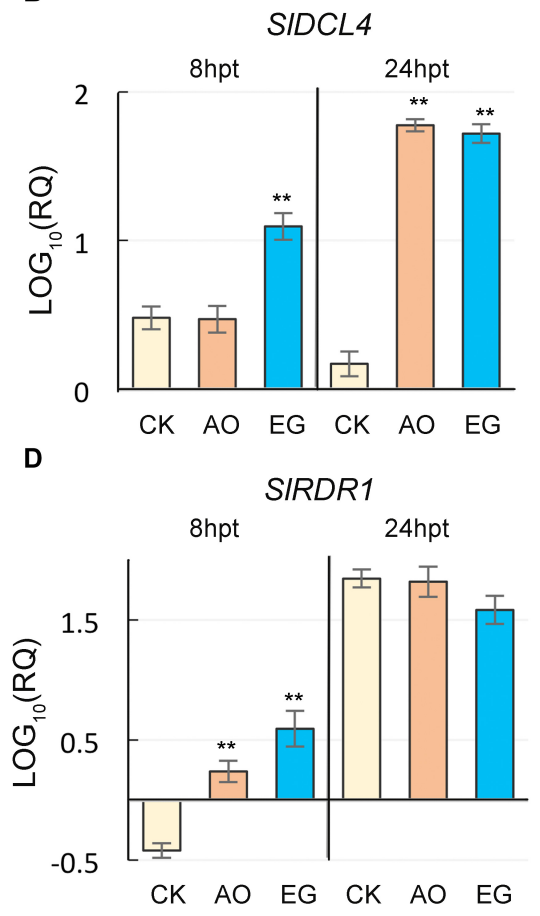

F

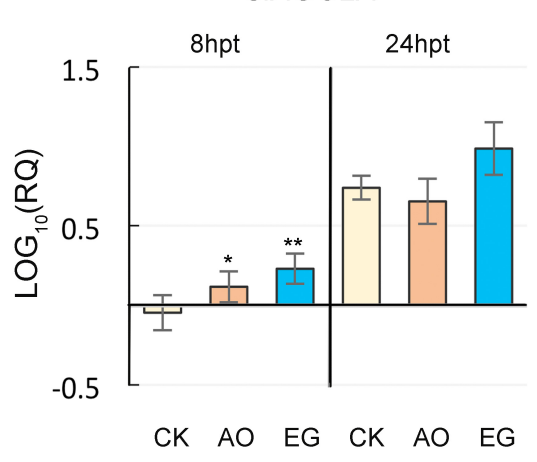

H

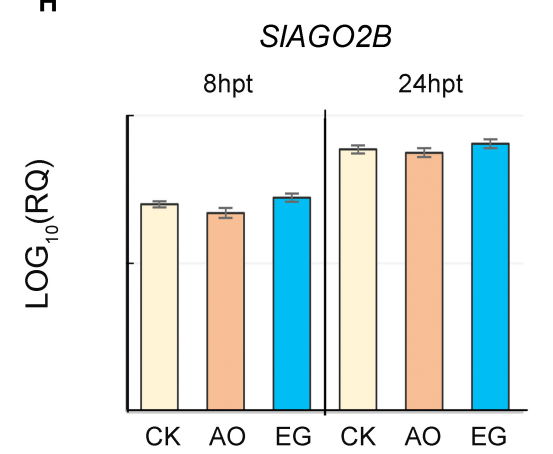

FIGURE 5 | Effects of anise oil and eugenol on the expression of RNA silencing genes in tomato plants. Fourteen-day-old tomato seedlings were treated with a control solution (CK), anise oil (AO), or eugenol (EG). Total RNA was extracted from these plants at $8 \mathrm{~h}$ post-treatment (hpt) and $24 \mathrm{hpt}$. The expression levels of RNA silencing genes, SIDCL2 (A), SIDCL4 (B), Ty-1 (C), SIRDR1 (D), SIAGO1A (E), SIAGO2A (F), SIAGO1B (G), and SIAGO2B (H) were analyzed by RT-qPCR. The $\beta$-actin expression level was used as the internal control. Relative gene expression levels were normalized against the expression level in untreated tomato plants. Data were analyzed with the $2^{-\Delta \Delta C t}$ method. Bars represent the mean ( \pm standard error of the mean) of three independent biological replicates each with three technical replicates. Significant differences between control and anise oil- or eugenol-treated plants were assessed with Student's $t$-test $\left({ }^{*} P<0.05 ;{ }^{* *} P<0.01\right)$. 

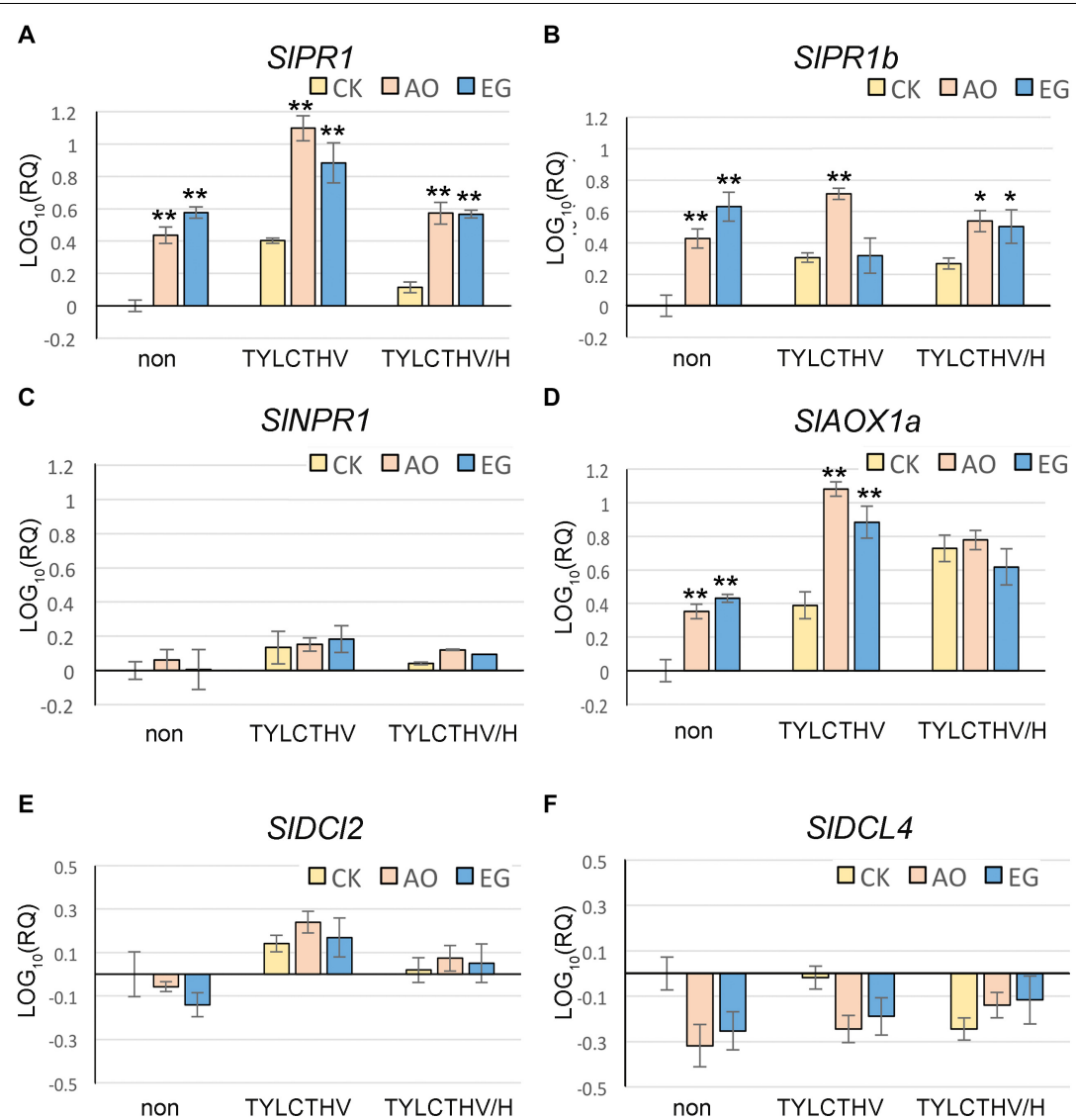

G

H
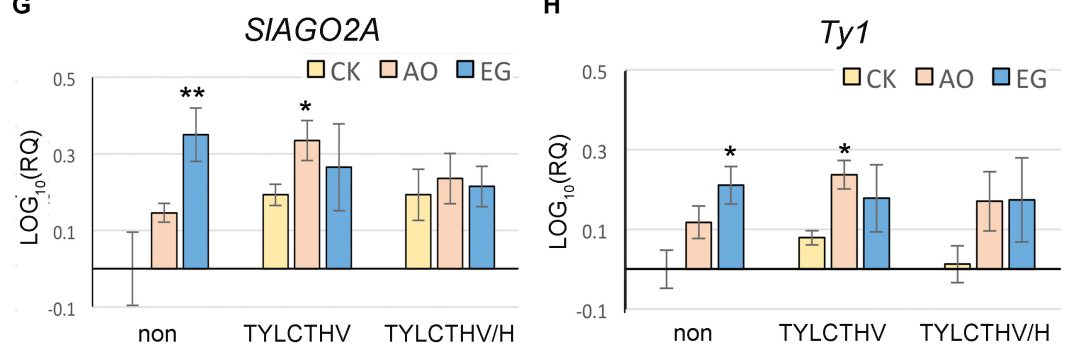

I

SIMPK3

$\square C K$ 口AO 口EG

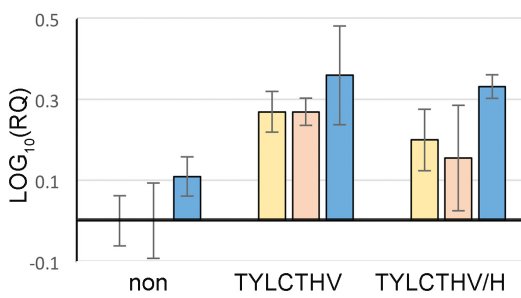

$\mathbf{J}$

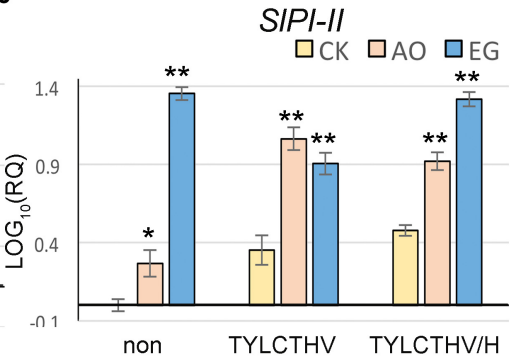

FIGURE 6 | Effects of anise oil and eugenol on the expression of defense-related genes in tomato plants under TYLCV infection with/without heat stress.

Fourteen-day-old tomato seedlings treated with a control solution (CK), eugenol (EG), or anise oil (AO) for $24 \mathrm{~h}$ were inoculated TYLCTHV. Then, some plants were incubated at $45^{\circ} \mathrm{C}$ for $12 \mathrm{~h}$. Total RNA was extracted from these plants. The expression levels of SA-related defense genes, SIPR1 (A), SIPR1b (B), SINPR1 (C), and SIAOX1a (D), RNA silencing genes, SIDCL2 (E), SIDCL4 (F), SIAGO2A (G), and Ty-1 (H), and JA-related defense genes, SIPI-II (I) and SIMAPK3 (J), were analyzed by RT-qPCR. The $\beta$-actin expression level was used as the internal control. Relative gene expression levels were normalized against the expression level in control. Data were analyzed with the $2^{-\Delta \Delta \mathrm{Ct}}$ method. Bars represent the mean ( \pm standard error of the mean) of three independent biological replicates each with three technical replicates. Significant differences between control and anise oil- or eugenol-treated plants were assessed with $S t u d e n t ' s t$-test $(* P<0.05 ; * * P<0.01)$. 

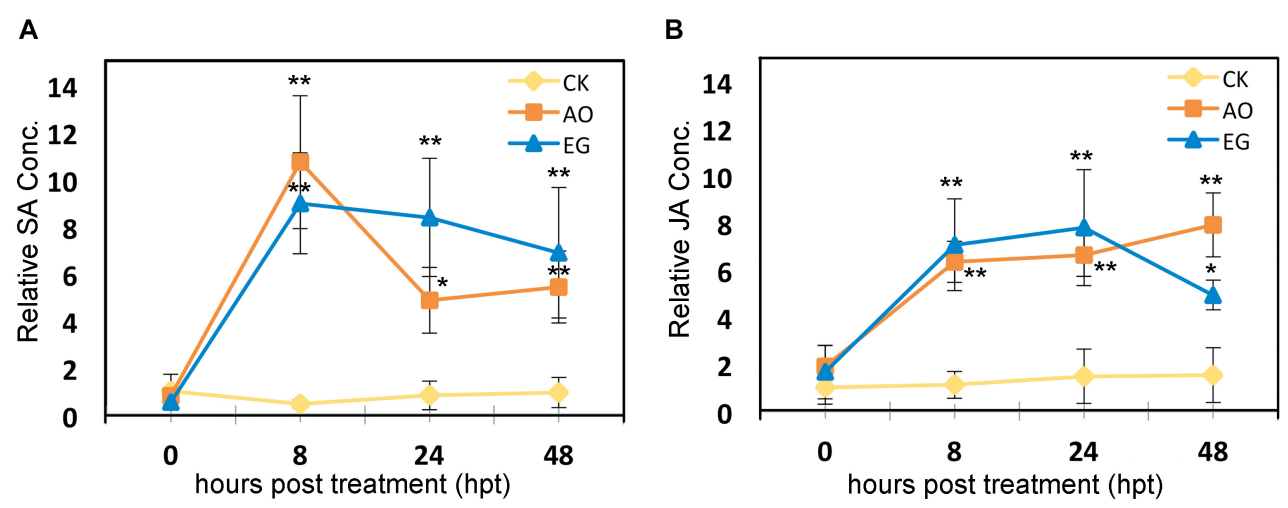

FIGURE 7 | Effects of anise oil and eugenol on the endogenous SA and JA contents. Fourteen-day-old tomato seedlings were treated with a control solution (CK), eugenol (EG), or anise oil (AO). The treated leaves were harvested just before the treatments ( $0 \mathrm{~h})$ and at 8,24 , and $48 \mathrm{~h}$ after treatments. The endogenous SA (A) and JA (B) contents were detected. The SA and JA levels of the untreated tomato plants was treated as the normalized reference, with a value of one. Bars represent the mean ( \pm standard deviation) from two measurements (each with triplicate samples). Significant differences between control and anise oil- or eugenol-treated plants were assessed with Student's $t$-test $\left({ }^{*} P<0.05\right.$; $\left.{ }^{* *} P<0.01\right)$.

effect to modulate the endogenous SA and JA contents in unstressed plants.

\section{Exogenous Application of Anise Oil and Eugenol Altered the Amounts of $\mathrm{H}_{2} \mathrm{O}_{2}$ in Tomato Leaves}

A rapid ROS burst is involved in early plant defense responses (Kadota et al., 2015). Among the ROS, $\mathrm{H}_{2} \mathrm{O}_{2}$ produced by the chloroplast is an important signaling molecule in response to diverse environmental stresses (Perez-Ruiz et al., 2006). There is evidence that SA induces the accumulation of $\mathrm{H}_{2} \mathrm{O}_{2}$, thereby increasing oxidative stress (Chao et al., 2010), and the increasing $\mathrm{H}_{2} \mathrm{O}_{2}$ level may also lead to SA biosynthesis (Leon et al., 1995). When SA and $\mathrm{H}_{2} \mathrm{O}_{2}$ accumulate to a high level, the local PR expression levels may also increase (Devadas and Raina, 2002). In this study, we examined whether the application of anise oil or eugenol affects the balance of ROS in tomato plants. Both anise oil and eugenol induced rapid generation of $\mathrm{H}_{2} \mathrm{O}_{2}$ in tomato leaves at 8 and $24 \mathrm{hpt}$ as indicated by the dark color in bleached leaves (Figure 8A). Furthermore, the titanium chloride method to quantify $\mathrm{H}_{2} \mathrm{O}_{2}$ revealed that anise oil and eugenol treatments could stimulate the generation of $\mathrm{H}_{2} \mathrm{O}_{2}$ in tomato leaves compared to the control (Figure 8B). In addition, expression of the antioxidant-associated genes, SIAPX2 and SICAT2, was also altered by anise oil and eugenol (Figures 8C,D). Overall, anise oil and eugenol may increase $\mathrm{H}_{2} \mathrm{O}_{2}$ accumulation to contribute to stress responses.

\section{DISCUSSION}

Some plant-derived materials reportedly enhance plant resistance against stresses (Bishop, 1995; Ertani et al., 2013; Vergnes et al., 2014). Eugenol, a natural plant-derived compound, may function as an anti-TYLCV agent in tomato plants (Wang and Fan, 2014; Sun et al., 2016). In this study, thermotolerancerelated phenotypes, including increased average fresh weight and survival rates, were observed in plants treated with exogenous anise oil or eugenol (Figure 1). Eugenol (Figures 2, 4, 7; Wang and Fan, 2014) and anise oil (Figures 2, 4, 7) appear to increase the SA content and upregulate the expression of a few downstream genes. Under heat stress, SA can influence the thermotolerance of crop plants (Larkindale et al., 2005; Wang et al., 2010; Khan et al., 2013). In Arabidopsis, SA regulates HSP17.6 to promote thermotolerance (Clarke et al., 2004). Anise oil and eugenol regulate the expression of HSFs and HSPs under heat stress (Figure 2). Thus, these findings suggest that eugenol and anise oil may act as priming agents and elevate the SA content to mediate the thermotolerance of tomato plants.

Tomato yellow leaf curl Thailand virus is the predominant tomato-infecting begomovirus in Taiwan (Tsai et al., 2011). Due to the lack of efficient priming agents, it is difficult to control TYLCTHV in the field. Previous studies have shown that eugenol is more effective as a protective agent than as a curative agent against TYLCV (Wang and Fan, 2014; Sun et al., 2016). Our results suggest that eugenol confers resistance not only to TYLCV but also TYLCTHV (Figure 3). We also observed that anise oil increases the resistance of tomato plants to TYLCTHV infections (Figure 3). The TYLCTHV incidence decreased by 75 and $60 \%$ following anise oil and eugenol $\left(200 \mu \mathrm{g} \mathrm{mL}^{-1}\right)$ treatments, respectively (Figure 3B). Our TYLCTHV DNA quantification (Figures 3C,D) showed that pre-treatment with anise oil or eugenol significantly reduced the accumulation rate of both TYLCTHV DNA-A and DNA-B. Consistent with the data provided in published reports, our qPCR analysis revealed that anise oil and eugenol inhibit the accumulation of DNAA to restrict TYLCTHV infection in seedlings (Figure 3C). Even though relative DNA-B amount showed no difference between these three treatments at $15 \mathrm{dpi}$, the lower DNA-A accumulation rate may have mitigated the symptom development (Figures 3A,C,D). In addition, the amounts of TYLCTHV DNA$B$ reached saturation more quickly in the control than in anise oiland eugenol-treated plants (Figure 3D). DNA-B of some bipartite begomoviruses, such as ToLCNDV also reached saturation at 


\section{A}
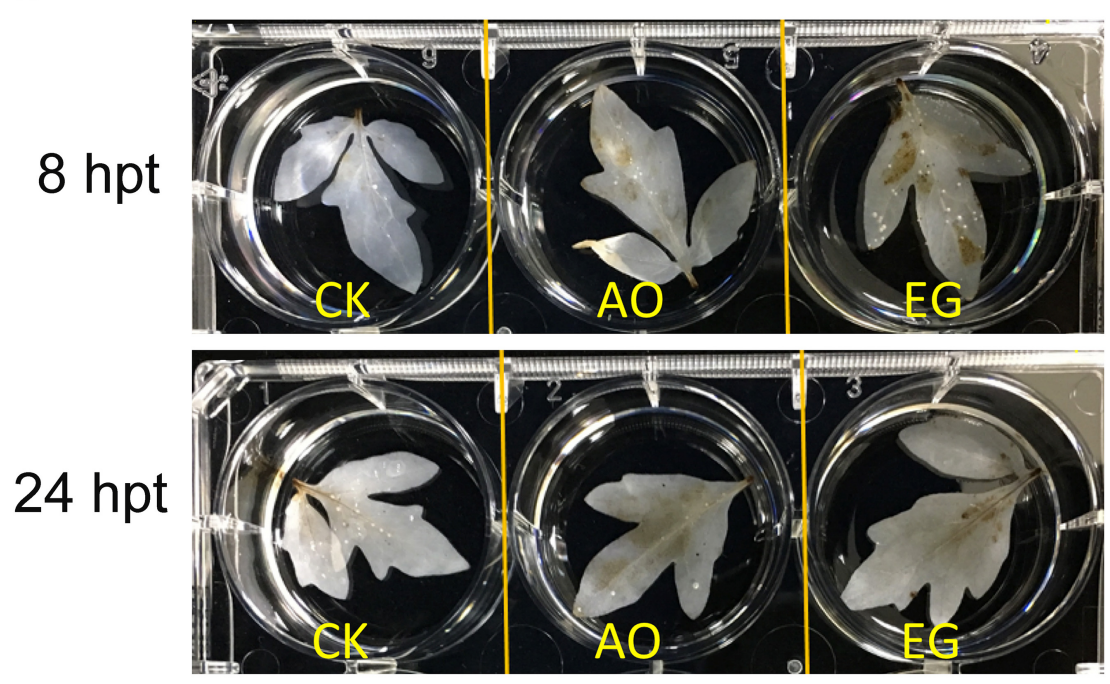

B

$8 \mathrm{hpt}$

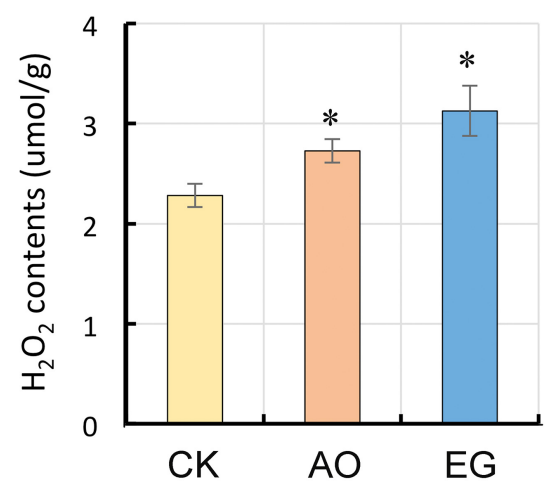

C

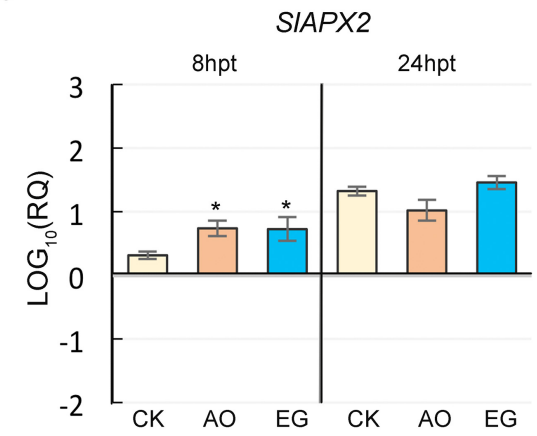

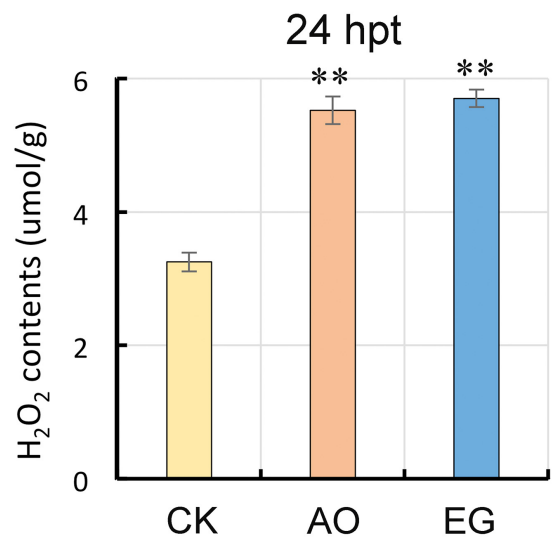

D

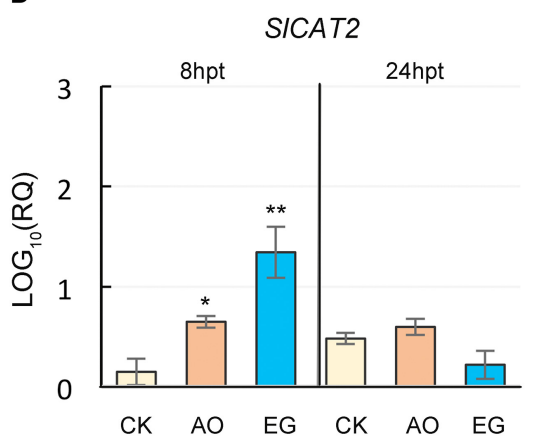

FIGURE 8 | Effects of anise oil and eugenol on the accumulation of $\mathrm{H}_{2} \mathrm{O}_{2}$ and the expression of antioxidant genes in tomato plants. 3'-Diaminobenzidine (DAB) staining was used to detect $\mathrm{H}_{2} \mathrm{O}_{2}$ in control, anise oil-, and eugenol-treated tomato plants at 8 hpt and 24 hpt (A). Furthermore, $\mathrm{H}_{2} \mathrm{O}_{2}$ content was quantified by titanium chloride method (B). In addition, expression of antioxidant genes, SIAPX2 (C) and S/CAT2 (D), was also analyzed by RT-qPCR. The $\beta$-actin expression level was used as the internal control. Relative gene expression levels were normalized against the expression level in untreated tomato plants. Data were analyzed with the $2^{-\Delta \Delta C t}$ method. Bars represent the mean ( \pm standard error of the mean) of three independent biological replicates each with three technical replicates. Significant differences between control and anise oil- or eugenol-treated plants were assessed with Student's $t$-test $\left({ }^{*} P<0.05 ;{ }^{* *} P<0.01\right)$.

10-14 dpi and showed a comparatively higher accumulation level than DNA-A (Jyothsna et al., 2013). This implies that TYLCTHV DNA-B has a higher accumulation rate than DNA-A regardless of treated plants or control plants (Figures 3C,D). Taken together, these findings suggest that the delayed accumulation of DNA-A and DNA-B in seedlings treated with anise oil or eugenol is 
responsible for mitigating the TYLCTHV disease and restricting the development of the characteristic symptoms.

Salicylic acid contributes to plant resistance against viral diseases and heat stress (Dat et al., 1998, 2000; Larkindale and Knight, 2002). Accordingly, the genes associated with thermotolerance and SAR defense responses have overlapping expression patterns (Clarke et al., 2004). The transcription of SA-related $P R$ defense genes is heat inducible and can be triggered by eugenol in response to TYLCV (Wang and Fan, 2014). A primed state induced by SA includes the activation of the mitogen activated kinase cascade, upregulation of $N P R 1$, and increased transcripts of $P R$ defense genes (Kohler et al., 2002; Yi et al., 2015). Here, elevated levels of SINPR1, SIPR1, SIPR1b, and SIAOX1a transcripts were recorded in anise oil- and eugenol-treated plants at 8 or $24 \mathrm{hpt}$ (Figures 4B-E). This suggests that anise oil and eugenol may be involved in the induction of SA responses. In addition, several studies have indicated that SA-mediated defense and RNA silencing may be connected (Baebler et al., 2014; Campos et al., 2014; Lee et al., 2016). SA can induce AGO2, AGO3, RDR1, DCL2 and DCL4, but has no effect on most of AGOs or RDRs in Arabidopsis seedlings (Alazem et al., 2019). After the application of exogenous SA and inoculation with TYLCV, SIDCL2 and SIDCL4 expressions were significantly upregulated (Li et al., 2018). Tomato plants silenced for SIDCL2-, SIDCL4-, and SIDCL2/4- showed increased susceptibility to TYLCV and reduced levels of SIPR1 and SlPR1b (Li et al., 2018). In this study, SlDCL2 and SlDCL4 transcript levels were increased in anise oil- and eugenoltreated plants compared to the control (Figures 5A,B). DCLs, $A G O s$, and $R D R s$ are crucial components in the RNA silencing machinery. However, the slightly increased $T y-1, S I R D R 1$, and SlAGO2A transcripts were recorded only at 8-h after anise oil and eugenol treatments (Figures 5C,D,F). These results raise the possibility that there are multiple factors affecting the RNA silencing pathway when plants are primed with anise oil and eugenol.

Reactive oxygen species have been implicated in mediating plant systemic signals in response to biotic and abiotic stresses (Gilroy et al., 2016). In the defense against viruses, SA induces an oxidative burst via the accumulation of $\mathrm{H}_{2} \mathrm{O}_{2}$, which may induce SAR (Chen et al., 1993; Nie et al., 2015). Respiratory burst oxidase homolog-dependent ROS can be activated by heat stress and may subsequently function as long-distance signals (Suzuki and Katano, 2018). Increased SA and $\mathrm{H}_{2} \mathrm{O}_{2}$ contents in anise oil- and eugenol-treated plants were observed in our study (Figures 7A, 8A,B). Plant resistance to TMV was demonstrated by the SA-dependent pathway with the AOX gene (Kachroo et al., 2000). Accordingly, SlAOX1a, and SlAOX1c expression were significantly upregulated at 24-h after anise oil and eugenol treatments (Figures 4E,F). This up-regulation was positively correlated with the accumulation of SA and $\mathrm{H}_{2} \mathrm{O}_{2}$ (Figures 7A, 8A,B). Thus, anise oil and eugenol enhanced the resistance of tomato plants to TYLCTHV and heat stress by activating SA-dependent signaling pathways.

Jasmonate is also an important viral defense hormone in plants (Alazem and Lin, 2015, 2017) and functions cooperatively with SA to confer basal thermotolerance in A. thaliana (Sharma and Laxmi, 2016). Interestingly, JA-mediated defenses against TYLCV seem to be more powerful than SA-mediated defenses in terms of viral transmission efficiency (Zarate et al., 2007; Li R. et al., 2014). The JA signaling pathway regulates the production of several plant secondary metabolites and defensive proteins that are harmful to herbivores (Zarate et al., 2007; Yang et al., 2008; Zhang et al., 2012). The suppression of JA-mediated defenses against $B$. tabaci, which is the vector for TYLCV transmission, may increase the number of viruliferous vectors produced and promote the transmission of the virus to new hosts (Su et al., 2016). TYLCCNV can promote the performance of whiteflies in infected tobacco plants by interfering with MYC2 dimerization and inhibiting the JA signaling pathway ( $\mathrm{Li} \mathrm{R}$. et al., 2014). Additionally, TYLCV enhances the performance of whiteflies in infected tomato plants by downregulating the expression of the JA-regulated defense gene SIPI-II (Sun et al., 2017). In this study, the expression of SlPPO-F and SlPI-II was upregulated by anise oil and eugenol treatments (Figures 4G,H). Similarly, JA contents also increased following anise oil and eugenol treatments (Figure 4B), which is consistent with the expression-level changes of the downstream genes. Therefore, these results suggest that the pre-application of anise oil or eugenol may alleviate TYLCTHV infection in tomato plants via whiteflies by modifying the JA content and the expression of JA-related genes.

Anise oil- and eugenol-activated SA- and JA-dependent signaling pathways were confirmed at the priming state due to the similar levels of SA and JA among both treatments under heat stress and TYLCTHV infection (Supplementary Figures S3A,B). Virus infection and temperature stress can interfere with the homeostatic balance, thus causing the accumulation of ROS in the apoplast (Awasthi et al., 2015; Carmo et al., 2017). This increase in ROS possibly activates plant defense response and overrides some of the priming effects caused by plantderived materials. Phytohormones appear to form a central hub that links, integrates, and re-programs multiple stress responses (Golldack et al., 2014). In this study, anise oil and eugenol enhanced the resistance of tomato plants to TYLCTHV infection and heat stress conditions at the priming state by activating two crucial defense hormones SA and JA. These two hormones and some of their downstream genes play a major role in plant defenses against TYLCV and heat stress (Clarke et al., 2004, 2009; Wang and Fan, 2014; Sun et al., 2016; Li et al., 2017).

The regulatory network underlying plant responses to stresses is much more complex than previously assumed. Even though previous studies showed that SA and JA are antagonistic hormones, there is increasing evidence that SA and JA do not have antagonistic activity against each other under some circumstances, including heat stress and TYLCV infection (Clarke et al., 2009; Su et al., 2016; Wang et al., 2017). TYLCV was found to suppress JA-mediated responses to B. tabaci via SA-independent mechanisms ( $\mathrm{Su}$ et al., 2016). In this study, we have shown that anise oil and eugenol can trigger SA- and JA-defense mechanisms to reduce the accumulation of TYLCTHV and enhance the heat stress tolerance of tomato plants. 


\section{AUTHOR CONTRIBUTIONS}

W-AT and J-SL developed the research concept, and wrote the manuscript. W-AT and S-HW performed most of the experiments. M-CC contributed to some experiments and revised the manuscript. W-ST provided the experimental materials and revised the manuscript. J-SL supervised the entire study. All authors have read and approved the final manuscript.

\section{FUNDING}

This research was supported by Council of Agriculture of Taiwan (Grant No. 107AS-1.2.7-ST-aK) and also supported by the Ministry of Science and Technology in Taiwan (Grant Nos. 106-2311-B-005-012 and 107-2311-B-005-008).

\section{REFERENCES}

Alazem, M., He, M. H., Moffett, P., and Lin, N. S. (2017). Abscisic acid induces resistance against Bamboo mosaic virus through Argonaute 2 and 3. Plant Physiol. 174, 339-355. doi: 10.1104/pp.16.00015

Alazem, M., Kim, K. H., and Lin, N. S. (2019). Effects of abscisic acid and salicylic acid on gene expression in the antiviral RNA silencing pathway in Arabidopsis. Int. J. Mol. Sci. 20:2538. doi: 10.3390/ijms20102538

Alazem, M., and Lin, N. S. (2015). Roles of plant hormones in the regulation of host-virus interactions. Mol. Plant Pathol. 16, 529-540. doi: 10.1111/mpp. 12204

Alazem, M., and Lin, N. S. (2017). Antiviral roles of abscisic acid in plants. Front. Plant Sci. 8:1760. doi: 10.3389/fpls.2017.01760

Ammad, F., Moumen, O., Gasem, A., Othmane, S., Hisashi, K. N., Zebib, B., et al. (2018). The potency of lemon (Citrus limon L.) essential oil to control some fungal diseases of grapevine wood. C. R. Biol. 341, 97-101. doi: 10.1016/j.crvi. 2018.01.003

Anfoka, G., Moshe, A., Fridman, L., Amrani, L., Rotem, O., Kolot, M., et al. (2016). Tomato yellow leaf curl virus infection mitigates the heat stress response of plants grown at high temperatures. Sci. Rep. 6:19715. doi: 10.1038/srep25284

Arnao, M. B., and Hernandez-Ruiz, J. (2014). Melatonin: plant growth regulator and/or biostimulator during stress? Trends Plant Sci. 19, 789-797. doi: 10.1016/ j.tplants.2014.07.006

Arnao, M. B., and Hernandez-Ruiz, J. (2018). Melatonin and its relationship to plant hormones. Ann. Bot. 121, 195-207. doi: 10.1093/aob/mcx114

Athar, H. U. R., Khan, A., and Ashraf, M. (2008). Exogenously applied ascorbic acid alleviates salt-induced oxidative stress in wheat. Environ. Exp. Bot. 63, 224-231. doi: 10.1016/j.envexpbot.2007.10.018

Atkinson, N. J., and Urwin, P. E. (2012). The interaction of plant biotic and abiotic stresses: from genes to the field. J. Exp. Bot. 63, 3523-3543. doi: 10.1093/jxb/ ers100

Awasthi, R., Bhandari, K., and Nayyar, H. (2015). Temperature stress and redox homeostasis in agricultural crops. Front. Environ. Sci. 3:1. doi: 10.3389/fenvs. 2015.00011

Baebler, S., Witek, K., Petek, M., Stare, K., Tusek-Znidaric, M., Pompe-Novak, M., et al. (2014). Salicylic acid is an indispensable component of the $\mathrm{Ny}-1$ resistancegene-mediated response against Potato virus $\mathrm{Y}$ infection in potato. J. Exp. Bot. 65, 1095-1109. doi: 10.1093/jxb/ert447

Bishop, C. D. (1995). Antiviral activity of the essential oil of Melaleuca alternifolia (Maiden amp; Betche) cheel (Tea Tree) against tobacco mosaic virus. J. Essent. Oil Res. 7, 641-644. doi: 10.1080/10412905.1995.9700519

Burgyan, J., and Havelda, Z. (2011). Viral suppressors of RNA silencing. Trends Plant Sci. 16, 265-272. doi: 10.1016/j.tplants.2011.02.010

Butterbach, P., Verlaan, M. G., Dullemans, A., Lohuis, D., Visser, R. G. F., Bai, Y. L., et al. (2014). Tomato yellow leaf curl virus resistance by Ty-1 involves increased cytosine methylation of viral genomes and is compromised by cucumber mosaic

\section{ACKNOWLEDGMENTS}

We would like to thank Chi-Jia Chiou (Hualien District Agricultural Research and Extension Station, Council of Agriculture, Executive Yuan, Hualien City, Taiwan) for assistance with the cultivation of TYLCTHV source plants. In addition, we would also like to thank Assoc. Prof. Ralf Dietzgen (Queensland Alliance for Agriculture and Food Innovation, The University of Queensland, Australia) for helpful comments and proofreading of the manuscript.

\section{SUPPLEMENTARY MATERIAL}

The Supplementary Material for this article can be found online at: https://www.frontiersin.org/articles/10.3389/fpls.2019.00906/ full\#supplementary-material

virus infection. Proc. Natl. Acad. Sci. U.S.A. 111, 12942-12947. doi: 10.1073/ pnas. 1400894111

Calil, I. P., and Fontes, E. P. B. (2017). Plant immunity against viruses: antiviral immune receptors in focus. Ann. Bot. 119, 711-723. doi: 10.1093/aob/mcw200

Camejo, D., Rodriguez, P., Morales, A., Dell'Amico, J. M., Torrecillas, A., and Alarcon, J. J. (2005). High temperature effects on photosynthetic activity of two tomato cultivars with different heat susceptibility. J. Plant Physiol. 162, 281-289. doi: 10.1016/j.jplph.2004.07.014

Campos, L., Granell, P., Tarraga, S., Lopez-Gresa, P., Conejero, V., Belles, J. M., et al. (2014). Salicylic acid and gentisic acid induce RNA silencing-related genes and plant resistance to RNA pathogens. Plant Physiol. Biochem. 77, 35-43. doi: 10.1016/j.plaphy.2014.01.016

Carmo, L. S. T., Murad, A. M., Resende, R. O., Boiteux, L. S., Ribeiro, S. G., JorrínNovo, J. V., et al. (2017). Plant responses to tomato chlorotic mottle virus: proteomic view of the resistance mechanisms to a bipartite begomovirus in tomato. J. Proteom. 151, 284-292. doi: 10.1016/j.jprot.2016.07.018

Chandrashekhara, S., Raj, S. N., Manjunath, G., Deepak, S., and Shetty, H. S. (2010). Seed treatment with aqueous extract of viscum album induces resistance to pearl millet downy mildew pathogen. J. Plant Interact. 5, 283-291. doi: 10.1080/ 17429140903556539

Chao, Y. Y., Hong, C. Y., and Kao, C. H. (2010). The decline in ascorbic acid content is associated with cadmium toxicity of rice seedlings. Plant Physiol. Biochem. 48, 374-381. doi: 10.1016/j.plaphy.2010.01.009

Chen, Z. X., Silva, H., and Klessig, D. F. (1993). Active oxygen species in the induction of plant systemic acquired-resistance by salicylic-acid. Science 262, 1883-1886. doi: 10.1126/science.8266079

Christou, A., Filippou, P., Manganaris, G. A., and Fotopoulos, V. (2014). Sodium hydrosulfide induces systemic thermotolerance to strawberry plants through transcriptional regulation of heat shock proteins and aquaporin. BMC Plant Biol. 14:42. doi: 10.1186/1471-2229-14-42

Clarke, S. M., Cristescu, S. M., Miersch, O., Harren, F. J. M., Wasternack, C., and Mur, L. A. J. (2009). Jasmonates act with salicylic acid to confer basal thermotolerance in Arabidopsis thaliana. New Phytol. 182, 175-187. doi: 10. 1111/j.1469-8137.2008.02735.x

Clarke, S. M., Mur, L. A., Wood, J. E., and Scott, I. M. (2004). Salicylic acid dependent signaling promotes basal thermotolerance but is not essential for acquired thermotolerance in Arabidopsis thaliana. Plant J. 38, 432-447. doi: 10.1111/j.1365-313X.2004.02054.x

Czosnek, H. (2007). Tomato Yellow Leaf Curl Virus Disease: Management, Molecular Biology, Breeding for Resistance. Dordrecht: Springer.

Dat, J. F., Foyer, C. H., and Scott, I. M. (1998). Changes in salicylic acid and antioxidants during induced thermotolerance in mustard seedlings. Plant Physiol. 118, 1455-1461. doi: 10.1104/pp.118.4.1455

Dat, J. F., Lopez-Delgado, H., Foyer, C. H., and Scott, I. M. (2000). Effects of salicylic acid on oxidative stress and thermotolerance in tobacco. J. Plant Physiol. 156, 659-665. doi: 10.1007/s00299-017-2100-9 
Devadas, S. K., and Raina, R. (2002). Preexisting systemic acquired resistance suppresses hypersensitive response-associated cell death in Arabidopsis hrll mutant. Plant Physiol. 128, 1234-1244. doi: 10.1104/pp.010941

Dias, A. S., Barreiro, M. G., Campos, P. S., Ramalho, J. C., and Lidon, F. C. (2010). Wheat cellular membrane thermotolerance under heat stress. J. Agron. Crop Sci. 196, 100-108. doi: 10.1111/j.1439-037X.2009.00398.x

Ertani, A., Pizzeghello, D., Francioso, O., Sambo, P., Sanchez-Cortes, S., and Nardi, S. (2014). Capsicum chinensis L. growth and nutraceutical properties are enhanced by biostimulants in a long-term period: chemical and metabolomic approaches. Front. Plant Sci. 5:375. doi: 10.3389/fpls.2014.00375

Ertani, A., Schiavon, M., Muscolo, A., and Nardi, S. (2013). Alfalfa plant-derived biostimulant stimulate short-term growth of salt stressed Zea mays L. plants. Plant Soil 364, 145-158. doi: 10.1007/s11104-012-1335-Z

Faoro, F., and Gozzo, F. (2015). Is modulating virus virulence by induced systemic resistance realistic? Plant Sci. 234, 1-13. doi: 10.1016/j.plantsci.2015.01.011

Filippou, P., Antoniou, C., Obata, T., Van Der Kelen, K., Harokopos, V., Kanetis, L., et al. (2016). Kresoxim-methyl primes Medicago truncatula plants against abiotic stress factors via altered reactive oxygen and nitrogen species signalling leading to downstream transcriptional and metabolic readjustment. J. Exp. Bot. 67, 1259-1274. doi: 10.1093/jxb/erv516

Foyer, C. H., Rasool, B., Davey, J. W., and Hancock, R. D. (2016). Cross-tolerance to biotic and abiotic stresses in plants: a focus on resistance to aphid infestation. J. Exp. Bot. 67, 2025-2037. doi: 10.1093/jxb/erw079

Gilroy, S., Białasek, M., Suzuki, N., Górecka, M., Devireddy, A. R., Karpiński, S., et al. (2016). ROS, Calcium, and electric signals: key mediators of rapid systemic signaling in plants. Plant Physiol. 171, 1606-1615. doi: 10.1104/pp.16.00434

Golldack, D., Li, C., Mohan, H., and Probst, N. (2014). Tolerance to drought and salt stress in plants: unraveling the signaling networks. Front. Plant Sci. 5:151. doi: 10.3389/fpls.2014.00151

Hedil, M., and Kormelink, R. (2016). Viral RNA silencing suppression: the enigma of Bunyavirus NSs proteins. Viruses 8:208. doi: 10.3390/v8070208

Hossain, M. A., Li, Z. G., Hoque, T. S., Burritt, D. J., Fujita, M., and Munne-Bosch, S. (2018). Heat or cold priming-induced cross-tolerance to abiotic stresses in plants: key regulators and possible mechanisms. Protoplasma 255, 399-412. doi: 10.1007/s00709-017-1150-8

Islam, M. M., Hoque, A., Okuma, E., Nasrin, M., Banu, A., Shimoishi, Y., et al. (2009). Exogenous proline and glycinebetaine increase antioxidant enzyme activities and confer tolerance to cadmium stress in cultured tobacco cells. J. Plant Physiol. 166, 1587-1597. doi: 10.1016/j.jplph.2009.04.002

Jana, S., and Choudhuri, M. A. (1982). Glycolate metabolism of three submersed aquatic angiosperms during ageing. Aquat. Bot. 12, 345-354. doi: 10.1016/03043770(82)90026-2

Jaubert, M., Bhattacharjee, S., Mello, A. F., Perry, K. L., and Moffett, P. (2011). ARGONAUTE2 mediates RNA-silencing antiviral defenses against potato virus $\mathrm{X}$ in Arabidopsis. Plant Physiol. 156, 1556-1564. doi: 10.1104/pp.111.178012

Jisha, K. C., and Puthur, J. T. (2016). Seed priming with beta-amino butyric acid improves abiotic stress tolerance in rice seedlings. Rice Sci. 23, 242-254. doi: 10.1016/j.rsci.2016.08.002

Jyothsna, P., Haq, Q. M., Singh, P., Sumiya, K. V., Praveen, S., Rawat, R., et al. (2013). Infection of tomato leaf curl New Delhi virus (ToLCNDV), a bipartite begomovirus with betasatellites, results in enhanced level of helper virus components and antagonistic interaction between DNA B and betasatellites. Appl. Microbiol. Biotechnol. 97, 5457-5471. doi: 10.1007/s00253-012-4685-9

Kachroo, P., Yoshioka, K., Shah, J., Dooner, H. K., and Klessig, D. F. (2000). Resistance to turnip crinkle virus in Arabidopsis is regulated by two host genes and is salicylic acid dependent but NPR1, ethylene, and jasmonate independent. Plant Cell 12, 677-690. doi: 10.1105/tpc.12.5.677

Kadota, Y., Shirasu, K., and Zipfel, C. (2015). Regulation of the NADPH oxidase RBOHD during plant immunity. Plant Cell Physiol. 56, 1472-1480. doi: 10. 1093/pcp/pcv063

Khan, M. I., Iqbal, N., Masood, A., Per, T. S., and Khan, N. A. (2013). Salicylic acid alleviates adverse effects of heat stress on photosynthesis through changes in proline production and ethylene formation. Plant Signal. Behav. 8:e26374. doi: $10.4161 / \mathrm{psb} .26374$

Ko, C. C., Hung, Y. C., and Wang, C. H. (2007). Sequence characterized amplified region markers for identifying biotypes of Bemisia tabaci (Hem., Aleyrodidae). J. Appl. Entomol. 131, 542-547. doi: 10.1111/j.1439-0418.2007. 01174.x
Kohler, A., Schwindling, S., and Conrath, U. (2002). Benzothiadiazole-induced priming for potentiated responses to pathogen infection, wounding, and infiltration of water into leaves requires the NPR1/NIM1 gene in Arabidopsis. Plant Physiol. 128, 1046-1056. doi: 10.1104/pp.010744

Kotak, S., Larkindale, J., Lee, U., von Koskull-Doring, P., Vierling, E., and Scharf, K. D. (2007). Complexity of the heat stress response in plants. Curr. Opin. Plant Biol. 10, 310-316. doi: 10.1016/j.pbi.2007.04.011

Larkindale, J., Hall, J. D., Knight, M. R., and Vierling, E. (2005). Heat stress phenotypes of Arabidopsis mutants implicate multiple signaling pathways in the acquisition of thermotolerance. Plant Physiol. 138, 882-897. doi: 10.1104/ pp. 105.062257

Larkindale, J., and Knight, M. R. (2002). Protection against heat stress-induced oxidative damage in Arabidopsis involves calcium, abscisic acid, ethylene, and salicylic acid. Plant Physiol. 128, 682-695. doi: 10.1104/pp.010320

Lee, W. S., Fu, S. F., Li, Z., Murphy, A. M., Dobson, E. A., Garland, L., et al. (2016). Salicylic acid treatment and expression of an RNA-dependent RNA polymerase 1 transgene inhibit lethal symptoms and meristem invasion during tobacco mosaic virus infection in Nicotiana benthamiana. BMC Plant Biol. 16:15. doi: 10.1186/s12870-016-0705-8

Leon, J., Lawton, M. A., and Raskin, I. (1995). Hydrogen peroxide stimulates salicylic acid biosynthesis in tobacco. Plant Physiol. 108, 1673-1678. doi: 10. 1104/pp.108.4.1673

Li, R., Weldegergis, B. T., Li, J., Jung, C., Qu, J., Sun, Y., et al. (2014). Virulence factors of geminivirus interact with MYC2 to subvert plant resistance and promote vector performance. Plant Cell 26, 4991-5008. doi: 10.1105/tpc.114. 133181

Li, T., Hu, Y., Du, X., Tang, H., Shen, C., and Wu, J. (2014). Salicylic acid alleviates the adverse effects of salt stress in Torreya grandis cv. Merrillii seedlings by activating photosynthesis and enhancing antioxidant systems. PLoS One 9:e109492. doi: 10.1371/journal.pone.0109492

Li, Y. Z., Muhammad, T., Wang, Y., Zhang, D. L., Crabbe, M. J. C., and Liang, Y. (2018). Salicylic acid collaborates with gene silencing to tomato defense against tomato yellow leaf curl virus (TYLCV). Pak. J. Bot. 50, 2041-2054.

Li, Y. Z., Qin, L., Zhao, J. J., Muhammad, T., Cao, H. H., Li, H. L., et al. (2017). SIMAPK3 enhances tolerance to tomato yellow leaf curl virus (TYLCV) by regulating salicylic acid and jasmonic acid signaling in tomato (Solanum lycopersicum). PLoS One 12:e0172466. doi: 10.1371/journal.pone.0172466

Lin, J. S., Kuo, C. C., Yang, I. C., Tsai, W. A., Shen, Y. H., Lin, C. C., et al. (2018). MicroRNA160 modulates plant development and heat shock protein gene expression to mediate heat tolerance in Arabidopsis. Front. Plant Sci. 9:68. doi: $10.3389 /$ fpls.2018.00068

Lin, J. S., Lin, H. H., Li, Y. C., King, Y. C., Sung, R. J., Kuo, Y. W., et al. (2014). Carbon monoxide regulates the expression of the wound-inducible gene ipomoelin through antioxidation and MAPK phosphorylation in sweet potato. J. Exp. Bot. 65, 5279-5290. doi: 10.1093/jxb/eru291

Makarova, S., Makhotenko, A., Spechenkova, N., Love, A. J., Kalinina, N. O., and Taliansky, M. (2018). Interactive responses of potato (Solanum tuberosum L.) plants to heat stress and infection with potato virus Y. Front. Microbiol. 9:2582. doi: $10.3389 /$ fmicb. 2018.02582

Mäkinen, K., Lohmus, A., and Pollari, M. (2017). Plant RNA regulatory network and RNA granules in virus infection. Front. Plant Sci. 8:2093. doi: 10.3389/fpls. 2017.02093

Meller, B., Kuznicki, D., Arasimowicz-Jelonek, M., Deckert, J., and FloryszakWieczorek, J. (2018). BABA-primed histone modifications in potato for intergenerational resistance to Phytophthora infestans. Front. Plant Sci. 9:1228. doi: 10.3389/fpls.2018.01228

Moury, B., Selassie, K. G., Marchoux, G., Daubeze, A. M., and Palloix, A. (1998). High temperature effects on hypersensitive resistance to tomato spotted wilt tospovirus (TSWV) in pepper (Capsicum chinense Jacq.). Eur. J. Plant Pathol. 104, 489-498.

Nie, S. J., Yue, H. Y., Zhou, J., and Xing, D. (2015). Mitochondrial-derived reactive oxygen species play a vital role in the salicylic acid signaling pathway in Arabidopsis thaliana. PLoS One 10:e0119853. doi: 10.1371/journal.pone. 0119853

Nover, L., and Scharf, K. D. (1997). Heat stress proteins and transcription factors. Cell Mol. Life Sci. 53, 80-103. doi: 10.1007/PL00000583

Orozco-Cardenas, M., and Ryan, C. A. (1999). Hydrogen peroxide is generated systemically in plant leaves by wounding and systemin via the octadecanoid 
pathway. Proc. Natl. Acad. Sci. U.S.A. 96, 6553-6557. doi: 10.1073/pnas.96.11. 6553

Park, J. Y., Kim, S. H., Kim, N. H., Lee, S. W., Jeun, Y. C., and Hong, J. K. (2017). Differential inhibitory activities of four plant essential oils on in vitro growth of Fusarium oxysporum $\mathrm{f}$. sp fragariae causing Fusarium wilt in strawberry plants. Plant Pathol. J. 33, 582-588. doi: 10.5423/PPJ.OA.06.2017.0133

Perez-Ruiz, J. M., Spinola, M. C., Kirchsteiger, K., Moreno, J., Sahrawy, M., and Cejudo, F. J. (2006). Rice NTRC is a high-efficiency redox system for chloroplast protection against oxidative damage. Plant Cell 18, 2356-2368. doi: 10.1105/tpc. 106.041541

Rojas, M. R., Gilbertson, R. J., Russell, D. R., and Maxwell, D. P. (1993). Use of degenerate primers in the polymerase chain-reaction to detect whiteflytransmitted geminiviruses. Plant Dis. 77, 340-347.

Rouphael, Y., Colla, G., Giordano, M., El-Nalchel, C., Kyriacou, M. C., and De Pascale, S. (2017). Foliar applications of a legume-derived protein hydrolysate elicit dose-dependent increases of growth, leaf mineral composition, yield and fruit quality in two greenhouse tomato cultivars. Sci. Hortic. 226, 353-360. doi: 10.1016/j.scienta.2017.09.007

Savvides, A., Ali, S., Tester, M., and Fotopoulos, V. (2016). Chemical priming of plants against multiple abiotic stresses: mission possible? Trends Plant Sci. 21, 329-340. doi: 10.1016/j.tplants.2015.11.003

Shang, J., Xi, D. H., Xu, F., Wang, S. D., Cao, S., Xu, M. Y., et al. (2011). A broad-spectrum, efficient and nontransgenic approach to control plant viruses by application of salicylic acid and jasmonic acid. Planta 233, 299-308. doi: 10.1007/s00425-010-1308-5

Sharma, M., and Laxmi, A. (2016). Jasmonates: emerging players in controlling temperature stress tolerance. Front. Plant Sci. 6:1129. doi: 10.3389/fpls.2015. 01129

Shi, Q., Bao, Z., Zhu, Z., Ying, Q., and Qian, Q. (2006). Effects of different treatments of salicylic acid on heat tolerance, chlorophyll fluorescence, and antioxidant enzyme activity in seedlings of Cucumis sativa L. Plant Growth Regul. 48, 127-135. doi: 10.1007/s10725-005-5482-6

Snyman, M., and Cronje, M. J. (2008). Modulation of heat shock factors accompanies salicylic acid-mediated potentiation of Hsp70 in tomato seedlings. J. Exp. Bot. 59, 2125-2132. doi: 10.1093/jxb/ern075

Su, Q., Mescher, M. C., Wang, S. L., Chen, G., Xie, W., Wu, Q. J., et al. (2016). Tomato yellow leaf curl virus differentially influences plant defence responses to a vector and a non-vector herbivore. Plant Cell Environ. 39, 597-607. doi: 10.1111 /pce. 12650

Sun, T. J., Lu, Y., Narusaka, M., Shi, C., Yang, Y. B., Wu, J. X., et al. (2015). A novel pyrimidin-like plant activator stimulates plant disease resistance and promotes growth. PLoS One 10:e0123227. doi: 10.1371/journal.pone.0123227

Sun, W. J., Lv, W. J., Li, L. N., Yin, G., Hang, X. F., Xue, Y. F., et al. (2016). Eugenol confers resistance to tomato yellow leaf curl virus (TYLCV) by regulating the expression of SlPer1 in tomato plants. New Biotechnol. 33, 345-354. doi: 10.1016/j.nbt.2016.01.001

Sun, Y. C., Pan, L. L., Ying, F. Z., Li, P., Wang, X. W., and Liu, S. S. (2017). Jasmonic acid-related resistance in tomato mediates interactions between whitefly and whitefly-transmitted virus. Sci. Rep. 7:566. doi: 10.1038/s41598-01700692-w

Suzuki, N., and Katano, K. (2018). Coordination between ROS regulatory systems and other pathways under heat stress and pathogen attack. Front. Plant Sci. 9:490. doi: 10.3389/fpls.2018.00490

Ton, J., van der Ent, S., van Hulten, M., Pozo, M., van Oosten, V., van Loon, L. C., et al. (2009). Priming as a mechanism behind induced resistance against pathogens, insects and abiotic stress. IOBC/WPRS Bull. 44, 3-13.

Tsai, W. S., Shih, S. L., Kenyon, L., Green, S. K., and Jan, F. J. (2011). Temporal distribution and pathogenicity of the predominant tomato-infecting begomoviruses in Taiwan. Plant Pathol. 60, 787-799. doi: 10.1111/j.1365-3059. 2011.02424.x

Varma, A., and Malathi, V. G. (2003). Emerging geminivirus problems: a serious threat to crop production. Ann. Appl. Biol. 142, 145-164. doi: 10.1111/j.17447348.2003.tb00240.x

Vergnes, S., Ladouce, N., Fournier, S., Ferhout, H., Attia, F., and Dumas, B. (2014). Foliar treatments with Gaultheria procumbens essential oil induce defense responses and resistance against a fungal pathogen in Arabidopsis. Front. Plant Sci. 5:477. doi: $10.3389 /$ fpls.2014.00477

Verlaan, M. G., Hutton, S. F., Ibrahem, R. M., Kormelink, R., Visser, R. G. F., Scott, J. W., et al. (2013). The tomato yellow leaf curl virus resistance genes Ty-1 and Ty-3 are allelic and code for DFDGD-class RNA-dependent RNA polymerases. PLoS Genet. 9:e1003399. doi: 10.1371/journal.pgen.1003399

Wang, C. M., and Fan, Y. J. (2014). Eugenol enhances the resistance of tomato against tomato yellow leaf curl virus. J. Sci. Food Agric. 94, 677-682. doi: 10. 1002/jsfa.6304

Wang, F., Wang, C., Zou, T., Xu, N., and Sun, X. (2017). Comparative transcriptional profiling of Gracilariopsis lemaneiformis in response to salicylic acid- and methyl jasmonate-mediated heat resistance. PLoS One 12:e0176531. doi: 10.1371/journal.pone.0176531

Wang, L. J., Fan, L., Loescher, W., Duan, W., Liu, G. J., Cheng, J. S., et al. (2010). Salicylic acid alleviates decreases in photosynthesis under heat stress and accelerates recovery in grapevine leaves. BMC Plant Biol. 10:34. doi: 10. 1186/1471-2229-10-34

Wang, L. J., and Li, S. H. (2006). Salicylic acid-induced heat or cold tolerance in relation to $\mathrm{Ca} 2+$ homeostasis and antioxidant systems in young grape plants. Plant Sci. 170, 685-694. doi: 10.1016/j.plantsci.2005.09.005

Wang, W. X., Vinocur, B., Shoseyov, O., and Altman, A. (2004). Role of plant heatshock proteins and molecular chaperones in the abiotic stress response. Trends Plant Sci. 9, 244-252. doi: 10.1016/j.tplants.2004.03.006

Weng, S. H., Tsai, W. S., Kenyon, L., and Tsai, C. W. (2015). Different transmission efficiencies may drive displacement of tomato begomoviruses in the fields in Taiwan. Ann. Appl. Biol. 166, 321-330. doi: 10.1111/aab.12185

Yang, J. Y., Iwasaki, M., Machida, C., Machida, Y., Zhou, X. P., and Chua, N. H. (2008). beta C1, the pathogenicity factor of TYLCCNV, interacts with AS1 to alter leaf development and suppress selective jasmonic acid responses. Genes Dev. 22, 2564-2577. doi: 10.1101/gad.1682208

Yasuda, M., Ishikawa, A., Jikumaru, Y., Seki, M., Umezawa, T., Asami, T., et al. (2008). Antagonistic interaction between systemic acquired resistance and the abscisic acid-mediated abiotic stress response in Arabidopsis. Plant Cell 20, 1678-1692. doi: 10.1105/tpc.107.054296

Yi, S. Y., Min, S. R., and Kwon, S. Y. (2015). NPR1 is instrumental in priming for the enhanced flg22-induced MPK3 and MPK6 activation. Plant Pathol. J. 31, 192-194. doi: 10.5423/PPJ.NT.10.2014.0112

Zarate, S. I., Kempema, L. A., and Walling, L. L. (2007). Silverleaf whitefly induces salicylic acid defenses and suppresses effectual jasmonic acid defenses. Plant Physiol. 143, 866-875. doi: 10.1104/pp.106.090035

Zhang, N., Sun, Q. Q., Zhang, H. J., Cao, Y. Y., Weeda, S., Ren, S. X., et al. (2015). Roles of melatonin in abiotic stress resistance in plants. J. Exp. Bot. 66, 647-656. doi: 10.1093/jxb/eru336

Zhang, T., Luan, J. B., Qi, J. F., Huang, C. J., Li, M., Zhou, X. P., et al. (2012). Begomovirus-whitefly mutualism is achieved through repression of plant defences by a virus pathogenicity factor. Mol. Ecol. 21, 1294-1304. doi: 10.1111/j.1365-294X.2012.05457.x

Zhu, Y., Qian, W. Q., and Hua, J. (2010). Temperature modulates plant defense responses through NB-LRR proteins. PLos Pathog. 6:e1000844. doi: 10.1371/ journal.ppat.1000844

Conflict of Interest Statement: The authors declare that the research was conducted in the absence of any commercial or financial relationships that could be construed as a potential conflict of interest.

Significance Statement: Plant-derived materials, eugenol and anise oil, may enhance tomato thermotolerance and restrict tomato yellow leaf curl Thailand virus replication by regulating salicylic acid- and jasmonic acid-mediated defenses.

Copyright (C) 2019 Tsai, Weng, Chen, Lin and Tsai. This is an open-access article distributed under the terms of the Creative Commons Attribution License (CC BY). The use, distribution or reproduction in other forums is permitted, provided the original author(s) and the copyright owner(s) are credited and that the original publication in this journal is cited, in accordance with accepted academic practice. No use, distribution or reproduction is permitted which does not comply with these terms. 